\title{
EL DESARROLLO DEL DEBIDO PROCESO EN LAS ACTUACIONES ADMINISTRATIVAS PARA LA FORMACIÓN DE CONTRATOS ESTATALES*
}

\author{
DEVELOPMENT OF DUE PROCESS IN \\ ADMINISTRATIVE PROCEEDINGS FOR \\ THE FORMATION OF STATE CONTRACTS
}

\author{
Jaime Eduardo Chaves-Villada**
}

Fecha de recepción: 3 de marzo de 2014 Fecha de aceptación: 14 de abril de 2014 Disponible en linea: 30 de junio de 2015

\section{Para citar este artículo/To cite this article}

Chaves-Villada, Jaime Eduardo, El desarrollo del debido proceso en las actuaciones administrativas para la formación de contratos estatales, 130 Vniversitas, 91-134 (2015). http://dx.doi.org/10.11144/Javeriana.vj130.ddpa doi:10.11144/Javeriana.vj130.ddpa

* Este artículo corresponde al resultado de la investigación realizada en el segundo año de doctorado que el autor cursó entre los años 2013 y 2014.

** Abogado, Pontificia Universidad Javeriana. Especialista en derecho administrativo y en derecho contencioso y sustantivo constitucional. Estudiante del doctorado en ciencias jurídicas en la misma universidad. Profesor de pregrado y posgrado de contratación estatal, derecho constitucional y derecho administrativo en la Universidad Javeriana, Universidad de la Sabana y Universidad Sergio Arboleda. 


\section{RESUMEN}

El presente artículo de reflexión tiene como objetivo analizar el derecho fundamental del debido proceso consagrado en el artículo 29 de la Constitución Política de Colombia de 1991, en las actuaciones administrativas que orientan la formación del contrato estatal. El documento realiza una reflexión sobre la aplicación de los elementos del derecho al debido proceso identificados por la jurisprudencia y la doctrina en las actuaciones administrativas y, en especial, las desarrolladas en la formación del contrato estatal. En la segunda parte del artículo, se desarrollará un estudio específico de la aplicación del debido proceso en las actuaciones administrativas, concretamente en los procedimientos expedidos por el gobierno nacional para el desarrollo de esas actuaciones administrativas, en el que se analizarán esas disposiciones frente a los elementos del debido proceso administrativo.

Palabras clave: debido proceso; procedimiento administrativo; contratación estatal; actuaciones administrativas 


\section{ABSTRACT}

The purpose of this reflection article is to analyze the fundamental right to due process, established in Article 29 of the Constitution of Colombia of 1991, in administrative actions aimed at drawing up state agreements. The documents reflects on the applications of law to due process, as identified by case law and legal principles in administrative actions, and particularly to those developed in drawing up state agreements. The second part of the article develops a specific study regarding the application of due process in administrative actions -specifically those issued by the national government for the development of said administrative actionsin which we will analyze those provisions in view of the elements of the administrative due process.

Keywords: due process; administrative proceeding; state contracting; administrative actions

\section{SUMARIO}

Introducción.- I. Alcance del debido proceso.- A. Debido proceso como derecho fundamental.- B. Debido proceso en las actuaciones administrativas.- II. EL DEBIDO PROCESO EN LAS ACTUACIONES ADMINISTRATIVAS PARA LA FORMACIÓN DE CONTRATOS DEL EstAdo.- $A$. Falta de criterio en la adopción de procedimientos.- $B$. Violación de los principios rectores de las actuaciones administrativas.- ConClusiones.- Bibliografía. 


\section{INTRODUCCIÓN}

La contratación que adelantan los Estados entendida como un instrumento para la ejecución de la función administrativa ${ }^{1}$, conlleva uno de los principales retos de regulación por parte de un ordenamiento jurídico. Así lo expresa Eduardo García de Enterría al manifestar que: "La gravedad del problema teórico del contrato administrativo es que en él se viene a condensar el problema entero del Derecho Administrativo, y en especial las tres cuestiones centrales de la modulación en su ámbito de instituciones procedentes del Derecho Civil, de la posición jurídica de la Administración como sujeto y de la aplicación a la misma del Derecho Privado"2. Lo anterior debido a que claramente aparecen en el escenario factores de interés general que deben ser considerados para justificar las razones mismas de los actos jurídicos que en torno a esta materia se desprenden ${ }^{3}$.

En cada Estado se desarrollan diferentes modelos contractuales, para que los órganos que conforman el aparato estatal puedan alcanzar los fines constitucionales que se les han encomendado. Estos actos jurídicos pueden entenderse como actos administrativos y contratos $^{4}$, instrumentos mediante los cuales se verá expresada la voluntad de las distintas autoridades.

En el caso colombiano, el procedimiento de contratación estatal se basa necesariamente en el derecho fundamental del debido proceso, puesto que desde el artículo 29 de la Constitución Política

1 Para el profesor Miguel S. Marienhoff los contratos estatales aparecen como el vínculo jurídico que el Estado contrae con los particulares para el cumplimiento de sus fines: "588. Para el cumplimiento de los fines administrativos, el Estado, a través de la Administración Pública, actúa o puede actuar en dos formas distintas: ejerce por sí mismo la actividad respectiva o utiliza al administrado o particular para que colabore con él. La colaboración que el Estado requiera del administrado puede ser forzosa o voluntaria: la primera da lugar a la carga pública o prestación personal obligatoria, e incluso podría determinar una requisición transitoria de dinero o de cosas, como ocurriría, por ejemplo, con el empréstito forzoso temporario o con el uso de cosas muebles o inmuebles, ya que este uso puede ser objeto de requisición, la segunda puede dar lugar a los contratos de la Administración Pública”. Miguel S. Marienhoff, Tratado de derecho administrativo, tomo III, Contratos de la administración pública teorías general y de los contratos en particular, 2 (Editorial Abeledo-Perrot, Ediciones Glem, Buenos Aires, 1965).

2 Eduardo García de Enterría Martínez-Carande, La figura del contrato administrativo, 41, Revista de administración pública, 99-130, 110-111 (1963). Disponible en: http://dialnet.unirioja. es/descarga/articulo/2113075.pdf

3 Al respecto, Juan Carlos Cassagne, Derecho administrativo, tomo II, 25 (Editorial Abeledo Perrot, Pontificia Universidad Javeriana, Colección Internacional, Bogotá, 2009).

4 Así lo explica el profesor Cassagne: Juan Carlos Cassagne, Derecho administrativo, tomo II, 98 (Editorial Abeledo Perrot, Pontificia Universidad Javeriana, Colección Internacional, Bogotá, 2009). 
se obliga la aplicación de un debido proceso en las actuaciones judiciales y administrativas 5 . Por esta razón, la formación de los actos jurídicos que genera el Estado en ejercicio de su función administrativa deberá sustentarse en un debido proceso. En otras palabras, tanto los actos administrativos como los contratos, previos a su expedición o perfeccionamiento, respectivamente, deberán agotar un procedimiento previo que garantice entre otras $\cos ^{6} s^{6}$ : participación ciudadana, publicidad, eficiencia, economía, transparencia, celeridad, etapas probatorias, etc. ${ }^{7}$

En esta medida, para los actos administrativos, se implementarán las disposiciones legales que los orienten entendiendo como regla general el Código de Procedimiento Administrativo y de lo Contencioso Administrativo ${ }^{8}$, en cambio para los contratos esta-

5 Artículo 29, Constitución política. Colombia, Constitución política (1991). Disponible en: http://www.alcaldiabogota.gov.co/sisjur/normas/Norma1.jsp?i=4125

6 Sin perjuicio de los principios generales de las actuaciones administrativas sustentadas desde el artículo 209 de la Constitución Política de Colombia y en el artículo 3 numeral 9 de la Ley 1437 de 2011, Código de Procedimiento Administrativo y de lo Contencioso Administrativo, en el derecho administrativo y de necesaria consulta en las actuaciones administrativas, hay otros principios subsidiarios para el ejercicio de esta. Por ejemplo, encontramos el principio de favorabilidad preceptuado en el artículo 29 de la Constitución Nacional de la siguiente forma: "En materia penal, la ley permisiva o favorable, aun cuando sea posterior, se aplicará de preferencia a la restrictiva o desfavorable", la cual fue aplicada finalmente en temas administrativos, gracias a numerosos conceptos emitidos por el Consejo de Estado y las altas Cortes. En particular, el concepto del Consejo de Estado 1454 de 2002, en cuanto a la aplicación de este principio en temas administrativos, determinó lo siguiente: "El principio de favorabilidad consagrado en el artículo 29 de la Constitución Nacional, debe aplicarse, como regla general, en los procesos disciplinarios y administrativos adelantados por las autoridades administrativas, salvo en aquellas materias que por su especial naturaleza no resulten compatibles con él, como es el caso, por ejemplo, de las disposiciones en que se decide sobre sanciones a imponerse por violación de las disposiciones sobre política económica". Consejo de Estado, Sala de Consulta y Servicio Civil, concepto 1454, 16 de octubre de 2002, consejera ponente Susana Montes de Echeverri. Disponible en: http://www.alcaldiabogota. gov.co/sisjur/normas/Norma1.jsp?i=38183

7 Para el profesor Allan R. Brewer-Carías, el debido procedimiento “...puede analizarse estudiando los siguientes principios fundamentales: en primer lugar, el principio del contradictorio; en segundo lugar, el derecho a la defensa en el procedimiento administrativo, en concreto; en tercer lugar, el principio de la gratuidad; en cuarto lugar, el principio de la motivación de los actos administrativos, pero su enfoque, en las leyes lo configura más como un mecanismo de garantía del derecho a la defensa, que de la pura racionalización administrativa; en quinto lugar, el principio de la confianza legítima, que empieza a tomar cuerpo en las leyes de procedimiento administrativo, conforme a la doctrina europea y, por último, el tema de la garantía de la tutela judicial efectiva y su relación con el principio del agotamiento de la vía administrativa, tema clásico en las regulaciones del contencioso administrativo y del procedimiento administrativo". Allan R. Brewer-Carías, Principios del procedimiento administrativo en América Latina, 262 (Universidad del Rosario, Colegio Mayor de Nuestra Señora del Rosario, Editorial Legis, Bogotá, 2003).

8 Colombia, Ley 1437 de 2011, por la cual se expide el Código de Procedimiento Administrativo y de lo Contencioso Administrativo, 47956 Diario Oficial, 18 de enero de 2011. Disponible en: 
tales, estas disposiciones serán establecidas por lo que en nuestro país se ha denominado Estatuto General de Contratación de la Administración Pública9. Estas disposiciones serán las encargadas de generar las garantías suficientes para el ejercicio de la función administrativa y la protección de derechos fundamentales de los ciudadanos. En ese sentido, José María Rodríguez de Santiago explica: "En nuestros estados contemporáneos y específicamente en un Estado Social de Derecho nos encontramos frente a la necesidad de generar garantías para la formación de la voluntad del Estado, no bajo una filosofía de Estado interventor, sino en las bases de un Estado Prestador"10. Sostiene el autor:

Desde hace décadas forma parte de la teoría general de los derechos fundamentales la idea de que la creación por el Estado de ciertas estructuras organizativas y procedimentales constituye una forma característica de dar efectividad a aquellos derechos en el moderno Estado prestacional. Los derechos fundamentales ya no se realizarían sobre todo frente al Estado interventor, sino que se desarrollan, en buena parte, en el Estado prestador, que debe encauzar su actividad a través de -y poner a disposición del ciudadano-formas de organización y procedimiento adecuadas para hacer valer esos derechos —ex ante- en la propia conformación de la prestación ${ }^{l l}$.

No obstante lo anterior y al concentrarse en las etapas previas para la formación de los contratos, se descubre una gran inconsistencia en el desarrollo del sistema jurídico colombiano, puesto que desde el año 1993 y especialmente a partir de 2007, las disposiciones jurídicas que orientan la materia se han convertido en un verdadero obstáculo para su aplicación, lo cual genera una gran falencia en el sistema y afecta claramente la garantía constitucional de un debido proceso.

http://www.alcaldiabogota.gov.co/sisjur/normas/Norma1.jsp?i=41249, http://www.secretariasenado.gov.co/senado/basedoc/ley_1437_2011.html

9 En Colombia se desarrollan diferentes regímenes de contratación estatal, puesto que la Ley 80 de 1993 y sus normas posteriores disponen esas excepciones. Al respecto, Iván DARío GóMEZ-LeE, El derecho de la contratación pública en Colombia. Análisis y comentarios al Decreto 1510 de 2013, 2-3 (Editorial Legis, Bogotá, 2012).

10 Al respecto, Fernando Garrido-Falla, Las transformaciones del régimen administrativo, 91 (Instituto de Estudios Políticos, Madrid, 1962).

11 José María Rodríguez de SAntiago, La administración del Estado social, 132 (Editorial Marcial Pons, Ediciones Jurídicas y Sociales, Madrid, 2007). 
Claro está, no en el sentido formal de su consagración sino en su sentido teleológico, por lo cual se puede afirmar que en Colombia ha imperado la ausencia de un debido proceso. Por esta razón, se hace absolutamente necesario materializar un estudio científico de lo que debe entenderse como debido proceso en las actuaciones administrativas para la formación del contrato, puesto que las autoridades encargadas de desarrollar estas actuaciones y los particulares involucrados en esta actividad, bien sea como participantes del proceso, oferentes, contratistas o simples ciudadanos, requieren la protección de este derecho fundamental consagrado por la Constitución Política ${ }^{12}$.

Adicionalmente, aplicar un procedimiento para la formación del acto jurídico constituye un deber legal en cabeza de las autoridades administrativas, que debe involucrar necesariamente una decisión justa; así lo define Jaime Orlando Santofimio-Gamboa al sostener que: "Dentro de este contexto, se debe entender entonces por debido proceso el más amplio sistema de garantías que procura, a través de la realización del derecho material, la obtención de decisiones justas"13. Allí se debe profundizar el desarrollo material del procedimiento, puesto que al no cumplirlo, la decisión justa quedará en duda y se ausentará en muchas ocasiones del acto jurídico, lo cual genera una grave inestabilidad del Estado de Derecho.

En el presente estudio, se presenta la importancia del derecho al debido proceso en las actuaciones administrativas previas a la formación de los contratos. Para ello, se presentará una muestra de la evolución del derecho al debido proceso como derecho fundamental y su aplicación en el derecho administrativo, pues el debido proceso si bien se fundamenta en la esencia del derecho fundamental

12 El debido proceso administrativo en la formación de la voluntad del Estado es de absoluta importancia, ya que su cumplimiento correlativamente genera igualdad de condiciones entre los participantes del procedimiento, igualdad que no se predica en la relación contratante (Estado)-contratista (particular) en el vínculo contractual. En este sentido, Benjamín Herrera explica: "En el contrato estatal se parte del principio contrario. La primacía del interés público sobre el interés particular hace que las partes de ese contrato sean por esencia desiguales, la intervención del Estado en su regulación está destinada preferentemente a preservar y reservar esa desigualdad". Benjamín Herrera, Régimen de la exorbitancia, en Estudios de profundización en contratación estatal, 169 (Pontificia Universidad Javeriana, Cámara de Comercio de Bogotá, Bogotá, 1997).

13 Jaime Orlando Santofimio-Gamboa, Tratado de derecho administrativo, tomo II, Acto Administrativo, procedimiento, eficacia, validez, 61 (Universidad Externado de Colombia, Bogotá, 2003). 
consagrado en el artículo 29 de la Constitución Política de Colombia, necesariamente debe adaptarse a los principios que la misma Carta establece para las actuaciones administrativas contempladas en el artículo 209, postulados que obligatoriamente deberá atender con mayor inclinación, puesto que los elementos consagrados en el artículo 29 si bien lo sustentan, no le son aplicables en todas las actuaciones administrativas.

De igual manera, el presente estudio hará referencia al debido proceso en las actuaciones administrativas que se desarrollan en la parte precontractual y a la crisis generada por factores como la excesiva reglamentación de formas en el proceso y la violación manifiesta a los postulados constitucionales del artículo 209 de la Constitución anteriormente señalado, esto con el fin de sustentar la importancia del estudio del derecho al debido proceso administrativo en estas actuaciones que a diario adelantan las autoridades competentes para ello.

\section{AlCANCE DEL DEBIdo PROCESO}

El debido proceso tiene como fundamento el otorgamiento de una garantía para que los particulares gocen de seguridad jurídica al enfrentarse al aparato judicial o a la toma de decisiones administrativas del Estado. En palabras de Luis Marcelo de Bernardis, es el desarrollo de una tutela jurisdiccional ${ }^{14}$, pero claramente no debe entenderse solo en decisiones judiciales sino también en las decisiones administrativas. Esta forma contemporánea de entender el debido proceso ha sido el resultado de siglos de esfuerzo empeñados en resaltar la importancia de sus elementos esenciales. Solo hasta el 15 de diciembre de 1971 la ratificación de la V Enmienda de la Constitución de los Estados Unidos de América, hizo referencia a la protección de un debido proceso en la toma de una decisión administrativa, esta es, la protección de la propiedad privada en caso de ocupación por parte del Estado ${ }^{15}$. Podría afirmarse que el mayor avance del debido proceso administrativo tiene su génesis

14 Luis Marcelo de Bernardis, La garantía procesal del debido proceso, 84 (Cultural Cuzco S.A. Editores, Lima, 1985).

15 Estados Unidos de América, Quinta enmienda de la Constitución, 15 de diciembre de 1971. Disponible en: http://www.gpo.gov/fdsys/pkg/GPO-CONAN-1992/pdf/GPO-CONAN-1992-7. pdf, http://www.archives.gov/espanol/constitucion.html 
en la Constitución Política de Estados Unidos, específicamente en la Quinta enmienda ${ }^{16}$.

Para hacer referencia al estudio del debido proceso, reconocido por la Constitución Política como derecho fundamental, obligatoriamente se presentará su desarrollo en las actuaciones administrativas.

\section{A. Debido proceso como derecho fundamental}

Jesús González-Pérez señala que el derecho al debido proceso: "es el derecho de toda persona a que se le haga justicia, a que cuando pretenda algo de otra, esta pretensión sea atendida por un órgano jurisdiccional, a través de un proceso con garantías mínimas"17. Así, el debido proceso es aquel derecho que reúne las garantías ineludibles para que la tutela judicial sea efectiva, garantías entre las que se destacan: i) la garantía del juez natural, en virtud de la cual el órgano judicial debe estar siempre adornado por características

16 No obstante lo mencionado, debe señalarse a título ilustrativo y sin desconocer otras, las diferentes disposiciones que han hecho referencia al debido proceso y su evolución: 1. Carta Magna, de 1215, artículo 39; 2. Petition of Rights, 7 de junio de 1628; 3. Declaración de los Derechos del Hombre y del Ciudadano, 1789, artículos 5, 6, 7 y 8; 4. Declaración Universal de Derechos Humanos, 1948, artículos 10 y 11 entre otros; 5. Pacto Internacional de Derechos Civiles y Políticos (PIDCP), de 1966; Pacto Internacional de Derechos Económicos, Sociales y Culturales (PIDESC), de 1966; 6. Convenio para la Protección de los Derechos Humanos y de las Libertades Fundamentales, 1950, artículo 6; 7. Convención Americana sobre Derechos Humanos de 1969, artículo 8. Inglaterra, Carta Magna, 15 de junio de 1215. Disponible en: http://www.constitution.org/eng/magnacar.htm, http://jorgemachicado.blogspot.com/2008/11/ la-carta-magna-de-juan-sin-tierra.html\#fulltext. Inglaterra, Petición de derechos, 7 de junio de 1628. Disponible en: http://www.constitution.org/eng/petright.htm, http://www.unav.es/ constitucional/Materiales/Petition\%20of\%20rights\%20(1628).pdf. Francia, Declaración de los Derechos del Hombre y del Ciudadano, 26 de agosto de 1789. Disponible en: http://www. legifrance.gouv.fr/Droit-francais/Constitution/Declaration-des-Droits-de-1-Homme-et-duCitoyen-de-1789, http://www.fmmeducacion.com.ar/Historia/Documentoshist/1789derechos. htm. Organización de Naciones Unidas, Declaración Universal de Derechos Humanos, 1948. Disponible en: http://www.un.org/es/documents/udhr/. Organización de Naciones Unidas, Pacto Internacional de Derechos Civiles y Políticos (PIDCP), 16 de diciembre de 1966. Disponible en: http://www.humanium.org/es/derechos-civiles-politicos/. Organización de Naciones Unidas, Pacto Internacional de Derechos Económicos, Sociales y Culturales (PIDESC), 16 de diciembre de 1966. Disponible en: http://www.humanium.org/es/pacto-internacional-dederechos-economicos-sociales-y-culturales/. Consejo de Europa, Convenio Europeo para la Protección de los Derechos Humanos y de las Libertades Fundamentales, 4 de noviembre de 1950. Disponible en: http://www.echr.coe.int/Documents/Convention_SPA.pdf. Organización de Estados Americanos, Convención Americana sobre Derechos Humanos, 22 de noviembre de 1969. Disponible en: http://www.oas.org/dil/esp/tratados_B-32_Convencion_Americana_sobre_Derechos_Humanos.htm

17 Jesús GonzÁlez-PÉRez, El derecho a la tutela jurisdiccional efectiva, 27 (2a ed., Editorial Civitas, Madrid, 1985). 
y requisitos de imparcialidad, independencia y plena jurisdicción; ii) el derecho de defensa, a la luz del cual se analiza la proyección de este derecho en las distintas fases del procedimiento, destacando aquí la prueba y la terminación del proceso, así como la invariabilidad de las sentencias y la aclaración y rectificación de errores cometidos; y iii) la garantía que exige un proceso sin dilaciones injustificadas, la cual no busca garantizar una justicia rápida, sino que se haga en el tiempo necesario que cumpla las demás exigencias del debido proceso $^{18}$.

Para Juan Monroy-Gálvez, es pertinente hacer una distinción entre tutela judicial antes del proceso o derecho al proceso y tutela judicial durante el proceso o en el proceso, entendiendo la primera como el deber del Estado de proveer a la sociedad de los presupuestos materiales y jurídicos indispensables para que el proceso judicial opere y funcione como la vía más adecuada para garantizar las libertades individuales en tanto en cuanto sean afectadas por el Estado o por particulares, y la segunda como aquel conjunto de garantías que el Estado debe asegurar a toda persona parte de un proceso, a fin de que esta pueda ejercer plenamente sus derechos, bien alegando, probando, impugnando o requiriendo ${ }^{19}$.

En Colombia, los artículos 10 y 14 del Título XII de la Constitución de Cundinamarca de 1811 consagraban disposiciones enfocadas en la protección de garantías preliminares para la expedición de decisiones por parte del Estado. Estos artículos se presentan así:

Título XII. De los derechos del hombre y del ciudadano

Artículo 10. Ninguno puede ser privado de la menor porción de sus bienes sin su consentimiento, sino en el caso de que la necesidad pública, legítimamente acreditada, así lo exija, pero aun entonces, es bajo la implícita condición de una justa y precisa indemnización.

Artículo 14. Ninguno puede ser llamado a juicio, acusado, preso, arrestado, arraigado ni confinado, sino en los casos y bajo las formas prescritas por la Constitución o la ley ${ }^{20}$.

18 Jesús GonzÁlez-PÉrez, El derecho a la tutela jurisdiccional efectiva, 27 (2a ed., Editorial Civitas, Madrid, 1985).

19 Juan Monroy-Gálvez, Introducción al proceso civil, I, 245-249 (Editorial Temis, Bogotá, 1996).

20 Colombia, Constitución de Cundinamarca, suscrita el 30 de marzo de 1811, promulgada el 4 de abril de 1811. Disponible en: http://www.cervantesvirtual.com/obra/constitucion-de- 
No obstante, solo hasta la promulgación de la Constitución Política de Colombia de 1991, el debido proceso se consolidó como un derecho fundamental con las consecuencias que ello genera. Claro está, tampoco se puede sostener que antes de la Carta Política de 1991 no había derecho al debido proceso, sino que desde 1991 se logra un desarrollo tan amplio como el que hoy podemos conocer ${ }^{21}$. Para Pedro Pablo Camargo, por ejemplo, durante la vigencia de la Constitución de 1886 el concepto de debido proceso difícilmente se podría justificar. Afirma el autor:

En suma, durante la vigencia de la Constitución de 1886 no hubo debido proceso y, por consiguiente, administración de justicia imparcial, pronta y eficaz. Lo que hubo fue un aparato represivo al servicio de las castas políticas en el poder y la plutocracia. Imperó la dictadura del estado de sitio del artículo 121 de la Carta $^{22}$.

Por su parte, la jurisprudencia de la Corte Constitucional se ha pronunciado de manera amplia y reiterada acerca del contenido, elementos y características del debido proceso y lo ha definido como:

El conjunto de garantías previstas en el ordenamiento jurídico, a través de las cuales se busca la protección del individuo incurso en una actuación judicial o administrativa, para que durante su trámite se respeten sus derechos y se logre la aplicación correcta de la justicia ${ }^{23}$.

Así mismo, entre los elementos más importantes de este derecho fundamental, esa Corporación ha reconocido y destacado: "i) la garantía del acceso libre y en igualdad de condiciones a la justicia, con el fin de lograr una pronta resolución judicial, y el derecho

cundinamarca-30-de-marzo-de-1811-y-promulgada-el-4-de-abril-de-1811--0/, http://www. cervantesvirtual.com/servlet/SirveObras/12478304311266051543213/p0000001.htm\#I_0_

21 En la Constitución de 1886, los artículos 26, 27 y 28 hacían referencia al derecho del debido proceso. Por su parte, el Decreto 01 de 1984 expedido como Código Contencioso Administrativo, hoy derogado por la Ley 1437 de 2011, establecía un debido procedimiento administrativo para la formación de la voluntad del Estado, aunado a todas las disposiciones que le precedieron. Colombia, Constitución política (1886). Disponible en: http://www.alcaldiabogota.gov.co/ sisjur/normas/Norma1.jsp?i=7153. Colombia, Decreto 01 de 1984, por el cual se reforma el Código Contencioso Administrativo, 36439 Diario Oficial, 10 de enero de 1984. Disponible en: http://www.alcaldiabogota.gov.co/sisjur/normas/Norma1.jsp?i=6543

22 Pedro Pablo Camargo, El debido proceso, 112 (2ª ed., Editorial Leyer, Bogotá, 2002).

23 Corte Constitucional, sentencia C-980-10, 1 de diciembre de 2010, magistrado ponente Gabriel Eduardo Mendoza-Martelo. Disponible en: http://www.corteconstitucional.gov.co/ relatoria/2010/c-980-10.htm 
a la jurisdicción, ii) la garantía del juez natural, iii) las garantías inherentes a la legítima defensa, iv) la determinación y aplicación de trámites y plazos razonables, v) la garantía de imparcialidad", autonomía e independencia de los jueces y autoridades ${ }^{24}$, así como la exigencia de un procedimiento establecido previamente en la ley, de manera que este derecho constituya un desarrollo del principio de legalidad que garantice así un límite al poder del Estado, en especial, respecto del ius puniendi ${ }^{25}$, y la necesidad de que se respeten las formas propias de cada juicio, se garanticen los derechos fundamentales y se preserve el "valor material de la justicia"26.

Con ello, en nuestro ordenamiento jurídico, se creó un derecho al debido proceso claramente definido, con un fundamento constitucional e histórico que lo nutren para convertirse en uno de los derechos fundamentales que más se invoca para el respeto de la dignidad de las personas y que tiene como fin el cumplimiento de parámetros ciertos de justicia dentro de un Estado de Derecho.

\section{B. Debido proceso en las actuaciones administrativas}

El debido proceso en sede administrativa se edifica como un estándar que constituye una garantía formal para los particulares, pues deben cumplirse todos los actos o fases del procedimiento que la ley exige para que una decisión pueda calificarse con validez a la luz de un ordenamiento jurídico ${ }^{27}$, como una garantía material, en cuanto otorga al administrado la certeza de que podrá hacer

24 Corte Constitucional, sentencia C-089-11, 16 de febrero de 2011, magistrado ponente Luis Ernesto Vargas-Silva. Disponible en: http://www.corteconstitucional.gov.co/relatoria/2011/c-089-11. htm. Corte Constitucional, sentencia C-731-05, 12 de julio de 2005, magistrado ponente Humberto Antonio Sierra-Porto. Disponible en: http://www.corteconstitucional.gov.co/ relatoria/2005/c-731-05.htm

25 Corte Constitucional, sentencia C-980-10, 1 de diciembre de 2010, magistrado ponente Gabriel Eduardo Mendoza-Martelo. Disponible en: http://www.corteconstitucional.gov.co/ relatoria/2010/c-980-10.htm. Corte Constitucional, sentencia T-460-92, 15 de julio de 1992, magistrado ponente José Gregorio Hernández-Galindo. Disponible en: http://www.corteconstitucional.gov.co/relatoria/1992/t-460-92.htm

26 Corte Constitucional, sentencia C-641-02, 13 de agosto de 2002, magistrado ponente Rodrigo Escobar-Gil. Disponible en: http://www.corteconstitucional.gov.co/relatoria/2002/c-641-02.htm

27 Enrique Rojas-Franco, El debido procedimiento administrativo, 67 Derecho PUCP, Revista de la Facultad de Derecho de la Pontificia Universidad Católica del Perú, 177-188, 184 (2011). Disponible en: http://revistas.pucp.edu.pe/index.php/derechopucp/article/view/3147/3513 
valer sus derechos en el escenario de la administración ${ }^{28}$. Para Juan Alfonso Santamaría-Pastor, el debido proceso en las actuaciones administrativas marca sin lugar a dudas una diferencia fundamental en la toma de decisiones del Estado y la de los particulares, puesto que la primera se debe necesariamente fundamentar en las formalidades que los procedimientos jurídicos enmarcan, so pena de materializar la invalidez del acto, mientras que en las segundas, esta consecuencia no es la jurídicamente relevante, al menos para terceros. Así lo explica el autor:

a) Uno de los rasgos más característicos de nuestro sistema administrativo, común a todos los regímenes inspiradores en modelo francés, consiste en que las Administraciones públicas actúan habitualmente con sujeción a formas rituales: toman sus decisiones y llevan a cabo su actuación de manera formal, observando un determinado procedimiento que se halla definido e impuesto coactivamente mediante normas jurídicas.

Esta circunstancia distingue a la Administración de las personas privadas, cuya actuación es, en principio, informal; es cierto que las grandes organizaciones privadas tienden a establecer, cada vez de manera más acusada, pautas formales en la actuación de sus integrantes, pero la eficacia de dichos procedimientos es una cuestión puramente interna y ajena al Derecho, de tal modo que su incumplimiento puede determinar, a lo sumo, la responsabilidad laboral de un empleado, pero no tiene por qué afectar, en principio, la validez de la decisión que se toma ${ }^{29}$.

Al respecto, Augusto Mario Morello afirma que la garantía del debido proceso dentro del procedimiento administrativo se encuentra satisfecha una vez el individuo ha sido notificado de la existencia del procedimiento que se le sigue y cuando, además, se le ha otorgado la oportunidad de ser oído y de probar, de algún modo, los hechos que creyere conducentes a su descargo ${ }^{30}$. Esto partiendo

28 Para Gaston Jèze, el incumplimiento del debido proceso en la actuación administrativa genera los actos jurídicos irregulares: "Resumiendo: en principio, hay inexistencia de acto jurídico siempre que falta uno de sus elementos esenciales, ya se trate de la manifestación de voluntad, ya del poder legal. Si la manifestación de voluntad o el poder legal existen, pero están irregularmente expresados o ejercidos, entonces nos hallamos ante un acto jurídico irregular". GASTON JÈZE, Principios generales del derecho administrativo: la técnica jurídica del derecho público francés, tomo I, 31 (Julio N. San Millán-Almagro, trad., Editorial Depalma, Buenos Aires, 1948).

29 Juan Alfonso Santamaría-Pastor, Principios de derecho administrativo, volumen II, 55 ( $3^{\text {a }}$ ed., Editorial Centro de Estudios Ramón Areces, S.A., Madrid, 2002).

30 Augusto Mario Morello, El proceso justo. Del garantismo formal a la tutela efectiva de los derechos, 230 (Abeledo-Perrot, Buenos Aires, 1994). 
de la base de que nuestro ordenamiento jurídico adopta un criterio funcional y no orgánico para limitar el ámbito de aplicación de la función administrativa ${ }^{31}$, lo cual implica que - de conformidad con el artículo 2 de la Ley 1437 de 2011 - realizará actuación administrativa una autoridad (entendida como órgano del Estado o particular) siempre y cuando ejerza función administrativa ${ }^{32}$.

Así las cosas, debe advertirse que si bien el debido proceso constituye un deber para la administración de ajustar su actuar a los principios y mandatos que gobiernan la función administrativa y determinan su competencia, también constituye una carga para los particulares de observar y utilizar los medios procesales que el mismo ordenamiento jurídico les otorga o, en defecto de esto, la carga de asumir las consecuencias adversas que se puedan derivar de la conducta omisiva de los mismos. En nuestro Estado contemporáneo, el debido proceso que se desarrolla en las actuaciones administrativas por mandato constitucional y que necesariamente vincula la formación de la voluntad que se plasma en el acto administrativo o en el contrato, es un requisito de validez del acto final que marca un cauce para la decisión que adopte el Estado. En este

31 Al respecto, sin que lo haya modificado la Ley 1437 de 2011, expresa Brewer-Carías: "Por supuesto, hablar de la Administración Pública exige precisar si esta debe definirse desde el punto de vista orgánico o funcional, y lo cierto, en general, es que las leyes de procedimiento administrativo han optado por un criterio orgánico para definir su ámbito de aplicación, siendo la excepción la definición de dicho ámbito de aplicación mediante criterios funcionales. Esta excepción se da, sin embargo, en el caso de Brasil y Colombia. La Ley de Brasil, en efecto, prescribe que los preceptos de la misma 'se aplican a los órganos de los Poderes Legislativos o Judicial de la Unión, cuando desempeñen la función administrativa' (Art. 1, Parágrafo 1). Por su parte, en Colombia, el Código Contencioso Administrativo, en el libro sobre Procedimientos Administrativos, prescribe que sus normas se aplican al ejercicio de la función administrativa, sea cual sea el órgano o entidad que la ejerza: puede tratarse de los órganos de todas las ramas del Poder Público, de entidades descentralizadas, de órganos desconcentrados de rango constitucional y de entidades privadas cuando unos y otros cumplan funciones administrativas (art. 1)". Allan R. Brewer-Carías, Principios del procedimiento administrativo en América Latina, 12 (Universidad del Rosario, Colegio Mayor de Nuestra Señora del Rosario, Editorial Legis, Bogotá, 2003). Brasil, Ley 9784, que regula el procedimiento administrativo en la administración pública federal, 29 de enero de 1999. Disponible en: http://www.planalto.gov.br/ccivil_03/leis/L9784.htm

32 Ley 1437 de 2011. "Artículo 2. Ámbito de aplicación. Las normas de esta parte primera del Código se aplican a todos los organismos y entidades que conforman las ramas del poder público en sus distintos órdenes, sectores y niveles, a los órganos autónomos e independientes del Estado y a los particulares, cuando cumplan funciones administrativas. A todos ellos se les dará el nombre de autoridades". Colombia, Ley 1437 de 2011, por la cual se expide el Código de Procedimiento Administrativo y de lo Contencioso Administrativo, 47956 Diario Oficial, 18 de enero de 2011. Disponible en: http://www.alcaldiabogota.gov.co/sisjur/normas/Norma1. jsp?i=41249, http://www.secretariasenado.gov.co/senado/basedoc/ley_1437_2011.html 
sentido, Eduardo García de Enterría y Tomás Ramón Fernández se apartan del concepto sustancial del procedimiento administrativo expuesto por Fernando Garrido-Falla sobre la ley española, así:

El procedimiento no se limita a articular entre sí todas esas finalidades e intervenciones diversas, asegura también entre todas ellas un orden determinado en el cual los distintos actos deben ser cumplidos hasta concluir en la resolución final.

De este modo, el procedimiento administrativo aparece como una ordenación unitaria de una pluralidad de operaciones expresadas en actos diversos realizados heterogéneamente (por la función, por la naturaleza) por varios sujetos u órganos, operaciones y actos que, no obstante su relativa autonomía, se articulan en orden a la producción de un acto decisorio final. Aparece, pues, en el procedimiento una distinción fundamental entre decisión final o resolución (LPC, art. 89) y actos procedimentales, los cuales adoptan una posición instrumental respecto de aquella. Unos y otros son actos administrativos, aunque con función y régimen diversos, y los actos procedimentales o de trámite gozan, no obstante estar ordenados a la producción final de la resolución, de singularidad y de la relativa autonomía (producen efectos procedimentales propios, tienen sus reglas propias de validez, incluso, en ocasiones, subprocedimientos especificos para su producción, tienen causa propia, pueden ser anulados independientemente, etc.).

Se rechaza así la llamada concepción "sustancial" del procedimiento, que intenta ver en este (por ejemplo, Garrido-Falla) la simple formación gradual de la voluntad administrativa como la resultante o integración de las voluntades de todos aquellos sujetos y órganos (ya hemos visto que no todos expresan voluntades necesariamente) que han participado en la operación procedimental. El procedimiento administrativo no es la expresión de un supuesto acto complejo unitario, desenvuelto en el tiempo y en el cual participan sujetos y órganos diversos, no es una "forma de integración" de una sola voluntad administrativa que se nutriese de diferentes procedencias, no es un acto compuesto. No es, en efecto, un acto complejo, es más bien un complejo de actos, todos ellos instrumentales o auxiliares del acto final resolutorio o conclusivo, sin mengua de su sustantividad jurídica independiente ${ }^{33}$.

\section{Así mismo vale la pena resaltar que el procedimiento adminis- trativo si bien se encuentra en desarrollo del derecho fundamental}

33 Eduardo García de Enterría \& Tomas Ramón Fernández, Curso de derecho administrativo, tomo I, 543 (Editorial Temis, Palestra, Bogotá, Lima, 2008). España, Ley 30/1992, Ley de Protección Civil, LPC, de 26 de noviembre, de Régimen Jurídico de las Administraciones Públicas y del Procedimiento Administrativo Común, 40300 Boletín Oficial del Estado, BOE, 27 de noviembre de 1992. Disponible en: http://www.boe.es/boe/dias/1992/11/27/pdfs/A4030040319.pdf 
al debido proceso establecido en el artículo 29 de nuestra Constitución Política, como también lo hace el proceso judicial, claramente tendrá unas diferencias muy grandes en cuanto a su sentido formal y sustancial ${ }^{34}$. En palabras de Ramón Parada:

... el primero supone siempre la existencia clara de un conflicto entre partes sobre la aplicación del Derecho - incluso en el proceso penal donde se articula el contradictorio a través del Ministerio Fiscal-, sino en el hecho de que el procedimiento administrativo en la mayor parte de los casos no es tanto un problema de la correcta aplicación del Derecho y de resolución de conflictos jurídicos cuanto también un cauce necesario de la buena gestión de los intereses públicos, como ocurre, por ejemplo, en los procedimientos de selección de proyectos de obras o de funcionarios. En todo caso, esta gestión de asuntos de interés público, por estar sometida al principio de legalidad, exige, a diferencia de la gestión privada, el cumplimiento de determinadas formalidades que, incorporadas al expediente, que no es otra cosa que el procedimiento ya documentado, permitirán después el control judicial de la actividad administrativa ${ }^{35}$.

Para el caso colombiano, el debido proceso en las actuaciones administrativas aparece en el ordenamiento jurídico en una época muy reciente. Ya que antes de las normas establecidas en el Decreto 01 de 1984, por virtud del cual se adoptó el Código Contencioso Administrativo, difícilmente podría predicarse su consagración legal. En este sentido, lo analiza la jurisprudencia del Consejo de Estado:

En efecto - en aras de la claridad y la precisión-, durante ese largo lapso algunas leyes ofrecieron garantías a las personas vinculadas a un procedimiento administrativo, de manera que el panorama preciso de esa época exige reconocer algunos momentos históricos especiales, para mostrar las subetapas en que se aplicó un naciente derecho al debido proceso administrativo. Entre ellas se destacan dos momentos: i) el periodo anterior a 1984 — año de expedición del

34 En este sentido y de igual manera, lo explica Luis Enrique Berrocal-Guerrero: “...diferencias que radican ante todo en la ausencia del carácter contencioso propio del proceso judicial, para el trámite del primero, debido, entre otros aspectos, a que en el procedimiento administrativo no hay partes enfrentadas, y principalmente a que la decisión que le pone fin no hace tránsito a cosa juzgada, de donde, sin perjuicio del debido proceso y del derecho de defensa, su regulación tiende a la flexibilidad e informalidad.

En el trámite del mismo no hay partes procesales propiamente dichas, aunque las atribuciones de los interesados o afectados son similares a las de ellas en el proceso judicial. La intervención de ellos en ese procedimiento no implica ejercicio del derecho de acción. De allí que no sea exacto decir que la administración es juez y parte en el procedimiento administrativo". LuIS Enrique Berrocal-Guerrero, Manual del acto administrativo: según la ley, la jurisprudencia y la doctrina, 328 ( $5^{\text {a }}$ ed., Librería Ediciones del Profesional, Bogotá, 2009).

35 Ramón Parada, Derecho administrativo, tomo I, Parte general, 217 (Marcial Pons, Ediciones Jurídicas y Sociales, Madrid, Barcelona 2000). 
Código Contencioso Administrativo (en adelante CCA)—, ii) y el que inicia desde allí y avanza hasta la Constitución Política de 1991.

Sobre el primero, se sabe que antes de 1984 las garantías del debido proceso prácticamente no existían, porque no se trataba de un derecho con presencia fuerte en materia administrativa, pero sobre el segundo se tiene que el nuevo código de procedimiento administrativo introdujo varios e importantes derechos que hacen parte del debido proceso, es el caso del derecho a que se comunique la iniciación de un procedimiento administrativo — arts. 14 y $28 \mathrm{CCA}$ - el derecho a impugnar las decisiones administrativas, a través de la denominada vía gubernativa - arts. 23 y 49 yss. CCA-, el derecho a un procedimiento previo a la toma de una decisión, en la medida en que se proscribieron las decisiones de plano - art. 35 CCA-, el derecho a presentar pruebas y a controvertirlas —arts. 34 y 56 CCA-, entre otras.

No obstante, estas disposiciones son insuficientes, en comparación con el universo de garantías que contempla el artículo 29 CP, con el que inició el actual período de la evolución del derecho al debido proceso, esta norma es sustancialmente más prolija en cuanto a los derechos que recoge. En efecto, las garantías que ofrece la Constitución vigente superan ampliamente, en número e intensidad, lo que en el pasado ofreció el derecho público a los procedimientos administrativos, de ahí su importancia histórica. Por eso, el siguiente período importante en esta historia empieza con la actual Constitución ${ }^{36}$.

Por su parte, la Corte Constitucional, en sentencia T-1263 de $2001^{37}$, señaló que el debido proceso, considerado un principio rector de la actuación administrativa del Estado, constituye una garantía infranqueable para todo acto en el cual se pretenda legítimamente imponer sanciones, cargas o castigos, y en cuanto tal, es considerado como un límite al abuso del poder de sancionar de la administración. Así, específicamente en materia administrativa, esa corporación ha expresado que los principios generales que conforman el derecho fundamental al debido proceso se aplican igualmente a todas las actuaciones administrativas que desarrolle la administración pública en cumplimiento de sus funciones y realización de sus objetivos y fines, de manera que se garanticen: i) el acceso a procesos justos y adecuados, ii) el principio de lega-

36 Consejo de Estado, Sección Tercera, expediente 45316, auto del 27 de febrero de 2013, consejero ponente Jaime Orlando Santofimio-Gamboa. Disponible en: https://www.dltribunaladmi nistrativodelmagdalena.com/images/Jurisprudencia/Consejo_de_Estado/Auto-45316.pdf

37 Corte Constitucional, sentencia T-1263-01, 29 de noviembre de 2001, magistrado ponente Jaime Córdoba-Triviño. Disponible en: http://corteconstitucional.gov.co/relatoria/2001/T-1263-01.htm 
lidad y las formas administrativas previamente establecidas, iii) los principios de contradicción e imparcialidad, y iv) los derechos fundamentales de los asociados ${ }^{38}$.

De la misma manera, la Corte ha precisado que la cobertura del debido proceso administrativo se extiende a todo el ejercicio que la administración pública debe desarrollar en la realización de sus fines y objetivos estatales, lo que implica que aquello abarca todas las manifestaciones que se refieren a la formación y ejecución de los actos, las peticiones que presenten los particulares y los procesos que adelante la administración con el fin de garantizar la defensa de los ciudadanos ${ }^{39}$. Al respecto, la jurisprudencia constitucional ha diferenciado entre las garantías previas y las posteriores que implica dicho derecho, entendiendo por las primeras, aquellas garantías mínimas que necesariamente deben cobijar la expedición y ejecución de cualquier acto o procedimiento administrativo, tales como el acceso libre y en condiciones de igualdad a la justicia, el juez natural, el derecho de defensa, la razonabilidad de los plazos y la imparcialidad, autonomía e independencia de los jueces; y por las segundas, la posibilidad de cuestionar la validez jurídica de una decisión administrativa, esto por medio de los recursos de la vía gubernativa y la jurisdicción contenciosa administrativa ${ }^{40}$. Todas las garantías enunciadas están orientadas a garantizar el correcto y adecuado ejercicio de la función administrativa, de conformidad con los preceptos constitucionales, legales o reglamentarios vigentes y los derechos de los ciudadanos. De la misma manera, tales garantías buscan evitar actuaciones abusivas o arbitrarias por parte de la administración mediante la expedición de actos administrativos que resulten contrarios a los principios del Estado Social de Derecho y que puedan lesionar derechos de los particulares, y constituyen un

38 Corte Constitucional, sentencia C-089-11, 16 de febrero de 2011, magistrado ponente Luis Ernesto Vargas-Silva. Disponible en: http://www.corteconstitucional.gov.co/relatoria/2011/c-089-11.htm

39 Corte Constitucional, sentencia T-1013-99, 10 de noviembre de 1999, magistrado ponente Alfredo Beltrán-Sierra. Disponible en: http://www.corteconstitucional.gov.co/ relatoria/1999/t-1013-99.htm. Corte Constitucional, sentencia T-009-00, 18 de enero de 2000, magistrado ponente Eduardo Cifuentes-Muñoz. Disponible en: http://www.corteconstitucional.gov.co/relatoria/2000/t-009-00.htm

40 Corte Constitucional, sentencia C-1189-05, 22 de noviembre de 2005, magistrado ponente Humberto Antonio Sierra-Porto. Disponible en: http://www.corteconstitucional.gov.co/ relatoria/2005/c-1189-05.htm 
contrapeso al poder del Estado en las actuaciones que desarrolle este frente a los particulares ${ }^{41}$.

No obstante lo anterior, si bien la jurisprudencia constitucional ha señalado que las garantías mínimas propias del derecho fundamental al debido proceso son aplicables al procedimiento administrativo y deben ser aseguradas con el fin de garantizar el equilibrio entre los sujetos que resultan involucrados en una decisión administrativa, también ha advertido sobre las importantes diferencias que existen entre cada procedimiento, derivadas estas de las distintas finalidades que persiguen ${ }^{42}$. En este sentido, la Corte Constitucional, en sentencia C-640-02 señaló que en la medida en que el debido proceso judicial busca la resolución de conflictos de orden jurídico, o la defensa de la supremacía constitucional o del principio de legalidad, mientras que el debido proceso administrativo tiene por objeto el cumplimiento de la función administrativa en beneficio del interés general, esta "dualidad de fines hace que el procedimiento administrativo sea, en general, más ágil, rápido y flexible que el judicial habida cuenta de la necesaria intervención de la Administración en diversas esferas de la vida social que requieren de una eficaz y oportuna prestación de la función pública"43. En este sentido, para el alto tribunal constitucional, ambos deben estructurarse como un sistema de garantías de los ciudadanos, en especial de las garantías que conforman el debido proceso. Agrega la jurisprudencia constitucional que es imposible trasladar mecánicamente los contenidos del debido proceso judicial al debido proceso administrativo con fundamento en que este está regido por una doble categoría de principios rectores de rango constitucional que el legislador debe tener en cuenta a la hora de diseñar los procedimientos administrativos, a saber: de un lado, las garantías adscritas al debido proceso (art. 29), y de otra, los principios que gobiernan el recto ejercicio de la función pública (art. 209) ${ }^{44}$.

41 Corte Constitucional, sentencia C-089-11, 16 de febrero de 2011, magistrado ponente Luis Ernesto Vargas-Silva. Disponible en: http://www.corteconstitucional.gov.co/relatoria/2011/c-089-11.htm

42 Corte Constitucional, sentencia C-610-12, 1 de agosto de 2012, magistrado ponente Luis Ernesto Vargas-Silva. Disponible en: http://www.corteconstitucional.gov.co/relatoria/2012/c-610-12.htm

43 Corte Constitucional, sentencia C-640-02, 13 de agosto de 2002, magistrado ponente Marco Gerardo Monroy-Cabra. Disponible en: http://www.corteconstitucional.gov.co/relatoria/2002/C-640-02.htm

44 Corte Constitucional, sentencia C-640-02, 13 de agosto de 2002, magistrado ponente Marco Gerardo Monroy-Cabra. Disponible en: http://www.corteconstitucional.gov.co/relatoria/2002/C-640-02.htm 
Sin embargo, en un esfuerzo por armonizar el debido proceso consagrado en el artículo 29 de la Constitución Política con el debido proceso administrativo, el Consejo de Estado ha desarrollado una gran interpretación de las disposiciones constitucionales para darles vida en la formación de la voluntad de la administración. En primer lugar, hay una importante aproximación frente a la aplicación de la favorabilidad entendida como un principio subsidiario de las actuaciones administrativas, aunque no está mencionado expresamente por el legislador en las disposiciones normativas. En el Concepto 1454 de 2002, en aras de la consagración de las garantías sustanciales y procesales a favor del investigado, la Sala de Consulta y Servicio Civil interpretó el principio de favorabilidad entre las actuaciones administrativas sancionatorias buscando con ello su aplicación incluso después de la ejecutoriedad del acto administrativo. Sostuvo el Consejo de Estado:

Por ello, para dar cumplimiento al mandato constitucional y aplicación al principio de favorabilidad, basta con que en el momento de definir administrativamente la o las sanciones procedentes respecto de cada uno de los correspondientes infractores de las normas sobre transporte, se dé aplicación a las disposiciones de las normas que resultan más favorables para ellos.

Así, si no se ha iniciado el proceso, como no desapareció la conducta tipificada sino que disminuyó la sanción a imponer, el proceso se debe iniciar y en el momento de decidir se aplicará la nueva norma que disminuye la sanción. Si el proceso ya se había iniciado y no se ha fallado o decidido, del mismo modo en el momento de la toma de la decisión se tendrá en cuenta la nueva norma que establece una sanción más favorable al inculpado. Si el proceso ya se había fallado y la sanción se cumplió no resulta posible disminuir la sanción, pues se cumplió conforme a las disposiciones entonces vigentes. Si se falló o decidió el proceso y la correspondiente providencia está en firme pero no se ha cumplido la sanción, corresponde realizar un nuevo pronunciamiento administrativo a fin de ajustar la sanción a la nueva norma más favorable, en actuación debidamente motivada fundada justamente en la existencia de esa nueva norma más favorable, previa solicitud del interesado ${ }^{45}$.

\footnotetext{
45 Consejo de Estado, Sala de Consulta y Servicio Civil, concepto 1454, 16 de octubre de 2002, consejera ponente Susana Montes de Echeverri. Disponible en: http://www.alcaldiabogota. gov.co/sisjur/normas/Norma1.jsp?i=38183
} 
Así mismo, desde sus jurisprudencias, el Consejo de Estado ha dado aplicación de los elementos que integran el debido proceso consagrado en la Constitución Política a las actuaciones administrativas en general y no solamente en las actuaciones administrativas sancionatorias, puesto que si bien se materializan en actuaciones diferentes, vale la pena tener en cuenta que no es posible desconocer su importancia en la formación de la voluntad de las autoridades. En este sentido se expresa el máximo tribunal de lo contencioso administrativo en la sentencia del 25 de julio de 2011 Radicación 20279 $\left(6217^{46}\right)$, en la que claramente es muy generosa la interpretación que realiza el máximo tribunal de lo Contencioso Administrativo para asimilar todos los postulados del debido proceso judicial en la normatividad que orienta las actuaciones administrativas; sin embargo, a nuestro juicio y en coherencia con los argumentos previamente presentados por la Corte Constitucional, se puede entender que el derecho del debido proceso como derecho fundamental o como una garantía procesal, se fundamenta en fines y circunstancias completamente diferentes a las sostenidas por las actuaciones administrativas, pero sin que en ningún caso se pueda interpretar que en estas se prescinde de un debido proceso.

En esa medida, habrá actuaciones administrativas que involucren elementos del derecho al debido proceso judicial, mas no todas las actuaciones administrativas se nutren de todos esos elementos. En jurisprudencia previa a la anteriormente citada, así lo expuso la misma Sala del Consejo de Estado:

Para la Sala no cabe duda que el debido proceso rige en todos los procedimientos administrativos, sin importar que sean sancionatorios o no ${ }^{47}$. Esta clasificación

46 Consejo de Estado, Sección Tercera, radicación 20279 (6217), sentencia de 25 de julio de 2011, consejera ponente Olga Melida Valle de De la Hoz. Disponible en: http://www.alcaldiabogota.gov. co/sisjur/normas/Normal.jsp?i=44039, http://190.24.134.114:8080/WebRelatoria/ce/index.xhtml

47 La Corte Constitucional ha sido del mismo criterio, porque en muchas decisiones, entre ellas la sentencia T-149-02, expresa que este derecho también se debe garantizar para definir la asignación o exclusión de un derecho aplicable a una persona: "En materia de prestaciones positivas del Estado, en desarrollo del principio de Estado social de derecho, el debido proceso administrativo cumple una función de primer orden. Quien puede ser beneficiario de una prestación estatal no puede ser privado de la misma sino mediante una decisión respetuosa del debido proceso.

Ahora bien, la Corte se pregunta si el derecho al debido proceso puede ser invocado para impedir que la administración prive a su titular de un beneficio legal que aún no ha sido reconocido a la persona. A primera vista podría pensarse que por tratarse de una mera expectativa no nos encontramos ante un interés susceptible de protección constitucional. No 
tiene incidencia para otros efectos, por ejemplo para determinar los derechos del debido proceso que rigen en unas y en otras actuaciones, comoquiera que es indiscutible que las garantías se potencializan en las primeras y se reducen en las segundas, por razones obvias. Así, en las actuaciones sancionatorias es exigible el derecho a la preexistencia de la falta y la sanción, pero en las no sancionatorias carece de espacio. Lo mismo aplica para el derecho a la presunción de inocencia, ya que en los procedimientos sancionatorios tiene aplicación plena, mientras que en los no sancionatorios carece de sentido introducirlo, porque allí no se imputa nada a quienes participan de ellos ${ }^{48}$.

\section{Para nuestro propósito, se puede asegurar que en el Estado Social de Derecho que orienta la normatividad de las actuacio-}

obstante, la exclusión injustificada de la persona y la vulneración de su derecho al debido proceso, se presenta no solo por la privación del beneficio ya reconocido, sino también por la negación de la oportunidad procesal para obtener dicho reconocimiento, pese a encontrarse en las circunstancias descritas por la ley o el reglamento. En efecto, cuando la persona alega que materialmente cumple con el supuesto de hecho de una norma jurídica que asigna un beneficio, la administración no puede privar a dicha persona del procedimiento debido para determinar si procede o no el reconocimiento del respectivo beneficio. Tal proceder priva ex ante a la persona del derecho al debido proceso administrativo dispuesto para decidir sobre el reconocimiento del beneficio legal, con lo que se desconocen los derechos fundamentales al debido proceso administrativo (art. $29 \mathrm{CP}$ ) y a la igualdad de trato (art. 13 inc. $1 \mathrm{CP}$ ), dada la exclusión injustificada del solicitante.

El que las normas legales denominen auxilio al beneficio no le resta derechos al interesado. La denominación del beneficio tampoco lo convierte en una simple gracia del Estado cuando la reglamentación de su asignación en lugar de librarla a la mera voluntad de la administración, define precisos requisitos para determinar a partir de criterios objetivos quiénes son los destinatarios del beneficio. Es lo que sucede con la reglamentación del auxilio para ancianos indigentes objeto de este proceso". Corte Constitucional, sentencia T-149-02, 1 de marzo de 2002, magistrado ponente Manuel José Cepeda-Espinosa. Disponible en: http://www.corteconstitucional.gov.co/relatoria/2002/t-149-02.htm

En esa misma línea de pensamiento, la sentencia T-525-06 indicó: “4.2. El derecho al debido proceso administrativo se traduce en la garantía que comprende a todas las personas de acceder a un proceso justo y adecuado, de tal manera que el compromiso o privación de ciertos bienes jurídicos por parte del Estado a sus ciudadanos no pueda hacerse con ocasión de la suspensión en el ejercicio de los derechos fundamentales de los mismos. Es entonces la garantía consustancial e infranqueable que debe acompañar a todos aquellos actos que pretendan imponer legítimamente a los sujetos cargas, castigos o sanciones como establecer prerrogativas. Si bien la preservación de los intereses de la administración y el cumplimiento de los fines propios de la actuación estatal son un mandato imperativo de todos los procedimientos que se surtan a este nivel, en cada caso concreto debe llevarse a cabo una ponderación que armonice estas prerrogativas con los derechos fundamentales de los asociados". Corte Constitucional, sentencia T-525-06, 11 de julio de 2006, magistrado ponente Clara Inés Vargas-Hernández. Disponible en: http://www.corteconstitucional.gov.co/relatoria/2006/t-525-06.htm

En la sentencia T-796-06, la Corte también admitió que en los procedimientos contractuales no sancionatorios - como la liquidación del contrato-, debe aplicarse el debido proceso, en este caso en su faceta de la posibilidad de presentar pruebas y controvertirlas. Corte Constitucional, sentencia T-796-06, 21 de septiembre de 2006, magistrado ponente Clara Inés VargasHernández. Disponible en: http://www.corteconstitucional.gov.co/relatoria/2006/t-796-06.htm

48 Consejo de Estado, Sección Tercera, radicación 16367, sentencia de 23 de junio de 2010, consejero ponente Enrique Gil-Botero. Disponible en: http://190.24.134.114:8080/WebRelatoria/ ce/index.xhtml 
nes administrativas, el derecho al debido proceso irradia todas las actuaciones que emanan de las autoridades competentes para adoptar decisiones en nombre de la Nación. Esas decisiones necesariamente deben estar fundamentadas en el debido proceso, pero como anteriormente se mencionó, este debido proceso goza de un doble fundamento constitucional, el establecido en el artículo 29 y el establecido en el artículo 209 de nuestra Carta Política. Esto implica que en toda actuación administrativa principalmente se cumplan estos mandatos constitucionales, pero claramente habrá una mayor obligación de cumplir los mandatos constitucionales del artículo 209, puesto que hace expresa remisión al actuar del Estado en las decisiones administrativas, alertando que no se podrán dejar de consultar los postulados del artículo 29, el cual consagra el derecho fundamental al debido proceso, pero que implica unos elementos para las actuaciones judiciales que en no todos los casos son aplicables a las actuaciones administrativas.

\section{EL DEBIDO PROCESO EN LAS ACTUACIONES ADMINISTRATIVAS PARA LA FORMACIÓN DE CONTRATOS DEL ESTADO}

Obligatoriamente, en el Estado Social de Derecho, la formación de voluntad para la celebración de contratos que celebre el Estado debe estar fundamentada en el debido proceso, el cual se desarrolla en los procedimientos que establezca el ordenamiento jurídico. Así lo entiende Santamaría-Pastor, al señalar que: "La actuación formalizada de las Administraciones públicas no solo se realiza mediante la emisión de actos unilaterales (reglamentos, actos administrativos), sino también a través de acciones concertadas con otros sujetos de Derecho. Al igual que los sujetos privados, la Administración celebra habitualmente convenios o contratos" ${ }^{\prime 4}$. Para nuestros efectos y sin desconocer las discusiones doctrinarias sobre la clasificación del acto administrativo por virtud de la cual se interpreta la existencia de actos administrativos bilaterales para incluir los contratos entre estos ${ }^{50}$, se parte de la diferencia que encontramos

49 Juan Alfonso Santamaría-Pastor, Principios de derecho administrativo, volumen II, 185 ( $3^{\text {a }}$ ed., Editorial Centro de Estudios Ramón Areces, S.A., Madrid, 2002).

50 Así lo expresa Augusto Ramón Chávez-Marín: "Una buena parte de la doctrina considera que el contrato administrativo es una especie del género acto administrativo. Así es como, al 
en la unilateralidad de voluntad que expresa el primero a diferencia del segundo ${ }^{51}$, en el que claramente aparecen dos manifestaciones de voluntad, pero con la similitud de encontrar un procedimiento administrativo previo para su formación.

La contratación pública que debe desarrollar el Estado, se torna de una importancia suprema en el desarrollo de las funciones del Estado, puesto que un ejercicio de funciones solamente mediante actos unilaterales (sean estos sentencias, leyes, actos administrativos, etc.), perdería completamente fundamento democrático; los contratos que celebran el Estado y los particulares por definición generan acuerdos de voluntades entre unos y otros, lo cual fortalece el Estado de Derecho en sus instituciones y en sus relaciones con los particulares. En este sentido, Carlos García-Oviedo y Enrique Martínez-Useros anotan:

\footnotetext{
hacer la clasificación de los actos administrativos desde el punto de vista de las voluntades que intervienen en su formación o elaboración, esos autores distinguen los actos administrativos unilaterales y los actos administrativos bilaterales, y consideran los primeros como 'aquellos que son producto de la voluntad exclusiva de la administración, es decir, que esta los expide sin el consentimiento de los particulares'. Se dice que los actos bilaterales 'son los que resultan de un acuerdo de voluntades entre la administración y los particulares o entre varias personas jurídicas pertenecientes a la administración, como es el caso típico de los contratos'. De esta forma, se considera que el contrato es una especie de la categoría general constituida por el acto administrativo, lo cual responde a la fórmula: acto administrativo bilateral = contrato. Pero aunque esta es una postura muy frecuente en la doctrina, hay quienes, en una visión que aquí se comparte, se separan de ella para afirmar lo contrario, es decir que el acto administrativo y el contrato constituyen dos categorías jurídicas diferentes e independientes de la actuación administrativa. Estos autores consideran, básicamente, que el acto administrativo es en esencia una manifestación unilateral de voluntad de la administración, de donde se excluye la concurrencia del particular para producir el acto jurídico correspondiente. Si el acto administrativo es por esencia unilateral, excluye lo que podría ser un acto administrativo de fuente bilateral. Este último tipo de acto envolvería entonces una contradicción con la esencia misma del acto administrativo". Augusto RAMÓN CHÁvezMARín, Los convenios de la administración: entre la gestión pública y la actividad contractual, 45-46 (Editorial Universidad del Rosario, Bogotá, 2008).

51 Así lo ha entendido nuestra jurisprudencia al determinar los elementos que integran los actos administrativos y los contratos, y uno de los puntos de quiebre para diferenciarlos es la manifestación de voluntad. En palabras del Consejo de Estado se sostuvo: "De un lado, porque ella se refiere al perfeccionamiento de los "actos administrativos" — inciso primero-, no al de los contratos estatales, de manera que no es pertinente aplicarla a una institución o figura completamente distinta, como es la contratación estatal. En efecto, los contratos estatales no son actos administrativos, de manera que la norma no podía aplicárseles. En tal sentido, un acto administrativo es una declaración unilateral de voluntad, amén de las otras características, al paso que los contratos son, por definición, actos bilaterales, de manera que por este solo presupuesto falla la identificación de estas dos formas de manifestación de la voluntad de la administración". Consejo de Estado, Sección Tercera, expediente 24897, sentencia de 19 de noviembre de 2012, consejero ponente Jaime Orlando Santofimio-Gamboa. Disponible en: https://www.dltribunaladministrativodelmagdalena.com/images/Jurisprudencia/Consejo_de_Estado/SENTENCIA_UNIFICACION_C.E._ACTIO_IN_REM_VERSO.pdf
} 
Es notorio, y en ello se halla muy característica calificación del sentido de nuestro ordenamiento jurídico, que la Administración adquiere cosas y recibe prestaciones a través de relaciones no contractuales, mas esta realidad en nada oscurece la de la situación del Estado contratante, o Administración-cliente, expresión utilizada por [George] Pequignot. El Estado compra y el Estado construye. El conjunto de las entidades públicas - ha escrito [Bernard] Chenot-constituye el más fuerte consumidor de la Nación, el más importante cliente de las empresas privadas.

Si en una sociedad colectivista, el Estado, único propietario, utiliza la decisión unilateral para conseguir los bienes que precisa, por el contrario, cuando subsiste la propiedad privada obtiene de esta las prestaciones que necesita y que el sector estatizado no puede ofrecerle. Para ello puede proceder por vía de actos de autoridad, pero también puede procurarse los bienes necesarios abandonando sus prerrogativas de imposición y utilizando el procedimiento del contrato. La decadencia del contrato - escribe [Francesco] Carnelutti- sería el síntoma más grave de la crisis del Derecho. El principio del contrato es el acuerdo. En el acuerdo jurídico se supera la antinomia entre dos sujetos, mediante el procedimiento de la autorregulación. Los contratantes se dan la Ley a símismos, son a la vez súbditos y soberanos. Y la salvación del contrato está en su transferencia del plano individual al colectivo.

A virtud de ello, la importancia de los contratos de la Administración, como fuentes de obligaciones de la misma, gana mayor relieve, tanto desde el punto de vista del derecho público como del privado, pues el tema de la contratación administrativa, aparte de una constante cuestión polémica, implica un criterio de contrastes y vinculaciones en la significación y posibilidades de uno y otro ordenamiento en el marco de la actuación administrativa ${ }^{52}$.

En esa medida y por la sensibilidad que implican las relaciones del Estado con los particulares, en las que el primero debe despojarse de su gran fortaleza y mantener una relación jurídicamente estable con sus contratistas, el debido proceso se convierte en un pilar de la actividad contractual puesto que esta implica diferentes actuaciones administrativas que se pueden identificar en tres momentos, a saber, a. la etapa precontractual, b. la etapa contractual, y c. la etapa poscontractual.

Principalmente para nuestros propósitos, se hará referencia a la gran afectación que ha sufrido el debido proceso en la etapa precontractual. Esta afectación se fundamenta en primer lugar en

52 Carlos García-Oviedo \& Enrique Martínez-Useros, Derecho administrativo, tomo II, 126127 ( $9^{\text {a }}$ ed., Editorial E.I.S.A., Madrid, 1968). 
la falta de criterio para definir el procedimiento aplicable y en segundo lugar, en la violación manifiesta de los principios rectores del debido proceso, contemplados en el artículo 209 de la Constitución Política, por los procedimientos adoptados.

\section{A. Falta de criterio en la adopción de procedimientos}

El debido proceso necesariamente debe contemplar la claridad de las etapas por virtud de las cuales se llegará a una determinada decisión ${ }^{53}$, en materia de contratación pública. Estas etapas consagran unas características especiales:

\section{a. Todas las modalidades de selección de contratistas necesariamente deben agotar unas etapas previas para la formación del acto juridico que celebre el Estado}

En esta medida, los procesos de licitación pública, selección abreviada, contratación directa, concurso de méritos y mínima cuantía necesariamente deben agotar unos momentos previos para el perfeccionamiento del contrato. Incluso en aquellos casos en los cuales se invoca una urgencia manifiesta para la satisfacción de necesidades del Estado, sus autoridades deben agotar un procedimiento previo que justifique esta expresión de voluntad ${ }^{54}$.

53 En desarrollo del principio de economía, el artículo 25 de la Ley 80 de 1993 establece la necesidad de orientar los procesos de selección de contratistas mediante etapas, de lo cual se deriva la prohibición legal de abstenerse de decidir, menciona esta disposición en su numeral segundo: "Artículo 25. Del Principio de Economía. En virtud de este principio: 2. Las normas de los procedimientos contractuales se interpretarán de tal manera que no den ocasión a seguir trámites distintos y adicionales a los expresamente previstos o que permitan valerse de los defectos de forma o de la inobservancia de requisitos para no decidir o proferir providencias inhibitorias". Colombia, Ley 80 de 1993, por la cual se expide el Estatuto General de Contratación de la Administración Pública, 41094 Diario Oficial, 28 de octubre de 1993. Disponible en: http://www.alcaldiabogota.gov.co/sisjur/normas/Norma1.jsp?i=304

54 A propósito de la urgencia manifiesta como causal de contratación directa y su natural excepción, el Consejo de Estado se pronunció en los siguientes términos: "En estas estipulaciones, se hace evidente el principio de la prevalencia del interés general, en este caso, por encima de las formalidades de las actuaciones administrativas, puesto que si aquel se halla afectado o en peligro de serlo, el régimen jurídico debe ceder y permitir que las soluciones se den en la mayor brevedad posible, así ello implique la celebración de contratos sin el cumplimiento de los requisitos legales de selección del contratista y aún, la ejecución de los mismos, sin que medie la formalidad del contrato escrito, si la gravedad de las circunstancias así lo exige". Consejo de Estado, Sección Tercera, expediente 14275 (05229), sentencia de 27 de abril de 2006, 


\section{b. Las etapas que se desarrollen previo a la celebración del acto jurídico deben someterse a términos preclusivos y competencia perentoria}

En este entendido, el principio de economía, consagrado en el artículo 25 de la Ley 80 de 1993, dispuso:

Artículo 25. Del principio de economía. En virtud de este principio:

1. En las normas de selección y en los pliegos de condiciones o términos de referencia para la escogencia de contratistas, se cumplirán y establecerán los procedimientos y etapas estrictamente necesarios para asegurar la selección objetiva de la propuesta más favorable. Para este propósito, se señalarán términos preclusivos y perentorios para las diferentes etapas de la selección y las autoridades darán impulso oficioso a las actuaciones ${ }^{55}$.

En aras de guardar la seguridad jurídica de los procesos y evitar que las etapas de cada procedimiento se tornen infinitas, es necesario que se dispongan términos obligatorios para la actuación de las partes que intervienen en la formación de la voluntad del Estado. Por ende, no es posible sostener que los términos establecidos para el cumplimiento de requisitos necesarios para la conformación de los diferentes requisitos que deben aportar tanto el Estado como los oferentes, se tornen dilatados, confusos e irrespetados, puesto que esto viola manifiestamente el cumplimiento del debido proceso. Así mismo, en cumplimiento del principio de legalidad, cada una de las etapas trazadas para el desarrollo del procedimiento implica el ejercicio de una competencia de tiempo, modo y lugar atribuida a las diferentes autoridades que asumen esa responsabilidad. En esta medida, cuando vence el término establecido para cada etapa, la competencia termina y no le será dado a la entidad volver a asumirla, puesto que perderá facultades para ello.

consejero ponente Ramiro Saavedra-Becerra. Disponible en: http://www.alcaldiabogota.gov. co/sisjur/normas/Normal.jsp?i=21362

55 Colombia, Ley 80 de 1993, por la cual se expide el Estatuto General de Contratación de la Administración Pública, 41094 Diario Oficial, 28 de octubre de 1993. Disponible en: http:// www.alcaldiabogota.gov.co/sisjur/normas/Norma1.jsp?i=304 


\section{c. Obligatoriedad de una decisión}

La apertura formal de un proceso de selección de contratistas genera la obligación correlativa de adoptar una decisión final respecto del proceso. Esto responde al principio de economía procesal, por virtud del cual una vez abierto formalmente el proceso, la autoridad responsable debe adoptar una decisión sobre la existencia o no de un ganador.

Claramente, no se pueden descartar las posibilidades de un proceso desierto en la medida en que se cumplan ciertas circunstancias $^{56}$, como: 1. falta de interesados en el proceso; 2 . falta de oferentes; 3 . no cumplimiento de los requisitos mínimos para participar en el proceso.

En buena parte, el cumplimiento de estas características genera el desarrollo de un proceso justo y adecuado, con una participación en condiciones de igualdad y libre competencia entre los participantes. En este sentido, a propósito de los principios que orientan la contratación estatal, el Consejo de Estado señaló como deber de las autoridades responsables: "cumplir y observar las formas propias de los procesos de selección, mediante el desarrollo de etapas taxativas que aseguran la selección objetiva de la propuesta más favorable, no dilatar injustificadamente el procedimiento y cumplir con los términos preclusivos y perentorios fijados, evaluar los ofrecimientos de acuerdo con reglas justas, claras y objetivas, motivar por la administración su actuación y darla a conocer, brindar la posibilidad de controvertir los informes y conceptos y presentar observaciones a los mismos, etc., deberes todos estos

56 A propósito de la declaratoria de desierta, en este momento solamente es posible en la medida en que los oferentes no cumplan los requisitos habilitantes establecidos por el pliego de condiciones en coherencia con el artículo 5 de la Ley 1150 de 2007. Colombia, Ley 1150 de 2007, por medio de la cual se introducen medidas para la eficiencia y la transparencia en la Ley 80 de 1993 y se dictan otras disposiciones generales sobre la contratación con Recursos Públicos, 46691 Diario Oficial, 16 de julio de 2007. Disponible en: http://www.alcaldiabogota.gov.co/sisjur/normas/Norma1.jsp?i=25678. Para el Consejo de Estado, la declaratoria de desierta de un proceso tampoco puede ser un instrumento para enmendar errores de la propia administración, así lo afirmó en jurisprudencia de 2010: "La Administración no está facultada para declarar desierta una licitación cuando las razones que invoca están por fuera de la ley, lo cual también permite afirmar que a las entidades públicas contratantes no les asiste competencia legal para declarar desierta una licitación con el objeto de salvar o enmendar un error cometido por ellas mismas en la planeación del procedimiento de selección del contratista". Consejo de Estado, Sección Tercera, radicación 16432, sentencia de 14 de abril de 2010, consejero ponente Mauricio Fajardo-Gómez. Disponible en: http://190.24.134.114:8080/WebRelatoria/ce/index.xhtml 
que se involucran en los principios de transparencia, economía y selección objetiva" ${ }^{\prime 5}$.

Infortunadamente, estos postulados no han sido observados por las autoridades competentes encargadas de reglamentar los procesos de selección de contratistas, en los que se desarrollen estos mandatos y han sido muchos los intentos infortunados por materializar la forma del debido proceso aplicado a la contratación estatal. Muestra de ello son los siguientes actos administrativos: d. Desde la expedición del Decreto 066 de $2008^{58}$, cuatro decretos reglamentarios han buscado establecer un procedimiento de contratación en los casos en que la cuantía del contrato no supere el 10\% de la menor cuantía de la entidad contratante; el primero de ellos fue derogado y los otros tres fueron declarados nulos por el Consejo de Estado, circunstancia que obligó al legislador a llegar al extremo de incluir en un aparte final del Plan Nacional de Desarrollo y Plan de Inversiones 2010-201459, un nuevo procedimiento para ese tipo de situaciones con la exigencia de una posterior reglamentación del gobierno nacional por mandato mismo de la disposición comentada, que se presentó en el Decreto 2516 de $2011^{60}$, derogado posteriormente por el Decreto 734 de $2012^{61}$, derogado a su turno por el Decreto 1510 de $2013^{62}$. e. La implementación del Registro Único de Proponentes y la reglamentación del Régimen de Garantías han causado varios inconvenientes. Para el primero, entre 2008 y 2009 se expidieron cinco decretos reglamentarios que posteriormente - con el fin

57 Consejo de Estado, Sala de lo Contencioso Administrativo, Sección Tercera, sentencia de 3 de diciembre de 2007, consejera ponente Ruth Stella Correa-Palacio.

58 Colombia, Decreto 066 de 2008, por el cual se reglamenta parcialmente la Ley 1150 de 2007 sobre las modalidades de selección, publicidad y selección objetiva, y se dictan otras disposiciones, 46873 Diario Oficial, 16 de enero de 2008. Disponible en: http://www.alcaldiabogota. gov.co/sisjur/normas/Norma1.jsp?i=28244

59 Artículo 274, Ley 1450 de 2011. Colombia, Ley 1450 de 2011, por la cual se expide el Plan Nacional de Desarrollo 2010-2014, 48102 Diario Oficial, 16 de junio de 2011. Disponible en: http://www.alcaldiabogota.gov.co/sisjur/normas/Norma1.jsp?i=43101

60 Colombia, Decreto 2516 de 2011, por el cual se reglamenta la selección de mínima cuantía, 48128 Diario Oficial, 12 de julio de 2011. Disponible en: http:/www.alcaldiabogota.gov.co/ sisjur/normas/Norma1.jsp?i=43309

61 Colombia, Decreto 734 de 2012, por el cual se reglamenta el Estatuto General de Contratación de la Administración Pública y se dictan otras disposiciones, 48400 Diario Oficial, 13 de abril de 2012. Disponible en: http://www.alcaldiabogota.gov.co/sisjur/normas/Normal.jsp?i=46940

62 Colombia, Decreto 1510 de 2013, por el cual se reglamenta el sistema de compras y contratación pública, 48854 Diario Oficial, 17 de julio de 2013. Disponible en: http://www.alcaldiabogota. gov.co/sisjur/normas/Norma1.jsp?i=53776 
de corregir todos los errores - fueron derogados por el decreto 1464 de $2010^{63} \mathrm{y}$, para el segundo, el gobierno ha necesitado otros cinco decretos reglamentarios que orientan el régimen de garantías que consagra el artículo 6 de la Ley 1150 de 2007. Estos decretos a su turno han sido derogados por el Decreto 734 de 2012, derogado por el Decreto 1510 de 2013, aún vigente.

Pero la preocupación y la desesperación son de tal magnitud que el 12 de julio de 2011 se sancionó la Ley $1474^{64}$, correspondiente al denominado Estatuto Anticorrupción, el cual entre otras disposiciones en su Capítulo VII implementa diferentes figuras tendientes a la modificación estructural de la contratación estatal en el país, establece tipos penales más severos, al crear nuevas inhabilidades e incompatibilidades, intensificar las obligaciones de los interventores, modifica las modalidades de selección del contratista, crea una nueva forma de evaluar en los procesos de licitación pública y procesos de menor cuantía, repite la normatividad sobre contratación de mínima cuantía de la Ley 1450 de 2011 correspondiente al Plan Nacional de Desarrollo ${ }^{65}$, y consagra nuevas medidas para anticipos y adiciones en los contratos estatales. Además, el gobierno nacional, mediante Decreto 2430 del año $2011^{66}$, creó un organismo asesor con el fin de obtener en el término de seis (6) meses un informe de recomendaciones para tratar de solucionar el estado de crisis que vive el país, que dejó como resultado la creación de la unidad administrativa especial Agencia Nacional de Contratación Pública —Colombia Compra Eficiente-, mediante el Decreto

63 Colombia, Decreto 1464 de 2010, por el cual se reglamenta parcialmente la Ley 1150 de 2007 en relación con la verificación de las condiciones de los proponentes y su acreditación para el Registro Único de Proponentes a cargo de las Cámaras de Comercio y se dictan otras disposiciones, 47696 Diario Oficial, 30 de abril de 2010. Disponible en: http://www.alcaldiabogota. gov.co/sisjur/normas/Norma1.jsp?i=39442

64 Colombia, Ley 1474 de 2011, por la cual se dictan normas orientadas a fortalecer los mecanismos de prevención, investigación y sanción de actos de corrupción y la efectividad del control de la gestión pública, 48128 Diario Oficial, 12 de julio de 2011. Disponible en: http:// www.alcaldiabogota.gov.co/sisjur/normas/Norma1.jsp?i=43292

65 El gobierno nacional expidió el decreto reglamentario 2516 de 2011. Colombia, Decreto 2516 de 2011, por el cual se reglamenta la selección de mínima cuantía, 48128 Diario Oficial, 12 de julio de 2011. Disponible en: http://www.alcaldiabogota.gov.co/sisjur/normas/Norma1. jsp?i=43309

66 Colombia, Decreto 2430 de 2011, por el cual se crea la Comisión de Expertos Redactora del Proyecto de Ley de Estatuto General de Contratación de la Administración Pública, 48123 Diario Oficial, 7 de julio de 2011. Disponible en: http://www.alcaldiabogota.gov.co/sisjur/ normas/Norma1.jsp?i $=43280$ 
4170 de $2011^{67}$, entidad encargada de orientar las políticas públicas de compras para el Estado colombiano. Evidentemente, este desbalance en la organización de los procesos de contratación afecta ostensiblemente el debido proceso que se aplica a las actuaciones administrativas de la actividad precontractual, ya que a los particulares no les es posible conocer con claridad en qué forma se orientará la decisión del Estado. En este sentido, incluso el máximo tribunal de lo contencioso administrativo expresó lo siguiente:

Estas son las razones por las que la Corporación hace un llamado respetuoso al Gobierno Nacional, para que corrija el rumbo en materia de contratación estatal y, por lo tanto, al margen de las modificaciones introducidas con la Ley 1150 de 2007 procure una estabilidad y seguridad jurídica en los reglamentos de esa normativa, ya que, a diferencia del objetivo inicial de la Ley 80 de 1993, se está incurriendo, de nuevo, en un excesivo detallismo y una asfixiante reglamentación que hace complejo el proceso contractual para todos sus intervinientes, lo que genera en el plano jurídico inestabilidad y en el plano económico sobrecostos y externalidades negativas ${ }^{68}$.

\section{B. Violación de los principios rectores de las actuaciones administrativas}

Sumado a lo anterior, los procedimientos adoptados en la reglamentación desarrollada por el gobierno nacional han sido completamente violatorios de los elementos constitucionales que integran el debido proceso administrativo que se aplica a la contratación pública con base en los artículos 29 y 209 de la Constitución Política. En efecto, el debido proceso administrativo se sustenta en los principios consagrados para el ejercicio de las actuaciones administrativas del artículo 209 de nuestra Carta Política; no obstante, debemos tener presente que estos postulados presentes hoy en nuestra Constitución, tienen su antecedente en el artículo 3 del Decreto 01 de 1984, por virtud del cual se expidió el Código Con-

67 Colombia, Decreto 4170 de 2011, por el cual se crea la Agencia Nacional de Contratación Pública - Colombia Compra Eficiente-, se determinan sus objetivos y estructura, 48242 Diario Oficial, 3 de noviembre de 2011. Disponible en: http://www.alcaldiabogota.gov.co/ sisjur/normas/Norma1.jsp?i=44643

68 Consejo de Estado, Sala de lo Contencioso Administrativo, Sección Tercera, radicación 21324, sentencia de 12 de junio de 2014, consejero ponente Enrique Gil-Botero. Disponible en: http://190.24.134.114:8080/WebRelatoria/ce/index.xhtml 
tencioso Administrativo, en el que encontramos la mención de los mismos principios que aparecen en la Constitución de 1991 y que posteriormente se repiten en el artículo 3 de la Ley 489 de $1998^{69}$ ya en vigencia de la nueva Constitución.

De igual manera, el nuevo Código Contencioso Administrativo, consagrado en la Ley 1437 de 2011, retoma estos postulados; en su artículo 3 trae los mismos principios mencionados en 1984, elevados a rango constitucional en el artículo 209, consagrados por el legislador de 1998 y complementados en esta nueva disposición. Sin perjuicio de desconocer toda la jurisprudencia que rodea esta materia y especialmente el mandato de la Sentencia C-818-11 ${ }^{70}$, por la cual la Corte Constitucional ordena al Congreso de la República dar trámite de Ley Estatutaria a las disposiciones que la Ley 1437 de 2011 establece para la regulación del Derecho de Petición, razón por la cual se expedirá una nueva disposición jurídica para el desarrollo de los principios que orientan las actuaciones administrativas.

Sin perjuicio del estudio que requiere cada uno de estos mandatos constitucionales que orientan las actuaciones administrativas, necesariamente en materia de contratación pública se debe hacer referencia a la grave afectación que se ha tornado en contra de elementos como la publicidad, la igualdad, la transparencia, la economía, la celeridad, etc., por los procedimientos administrativos establecidos para adelantar la selección de contratistas, ya que en los diferentes actos administrativos que se han encargado de la materia se establecen disposiciones que flagrantemente van en contra de los mandatos constitucionales. En algunos casos, el Consejo de Estado ha contribuido a su protección; pero en otros, este mismo tribunal - por medio de sus providencias - ha llegado a afectarlos. A título de ejemplo, se puede ver el procedimiento de subasta inversa para la compra de bienes o servicios de características técnicas uniformes y de común utilización que se establece como causal de selección abreviada. Partimos de la base establecida

69 Colombia, Ley 489 de 1998, por la cual se dictan normas sobre la organización y funcionamiento de las entidades del orden nacional, se expiden las disposiciones, principios y reglas generales para el ejercicio de las atribuciones previstas en los numerales 15 y 16 del artículo 189 de la Constitución Política y se dictan otras disposiciones, 43464 Diario Oficial, 30 de diciembre de 1998. Disponible en: http://www.alcaldiabogota.gov.co/sisjur/normas/Normal.jsp?i=186

70 Corte Constitucional, sentencia C-818-11, 1 de noviembre de 2011, magistrado ponente Jorge Ignacio Pretelt-Chaljub. Disponible en: http://www.corteconstitucional.gov.co/ RELATORIA/2011/C-818-11.htm 
en el artículo 2 de la Ley 1150 de 2007, en el que por regla general de contratación aparece la licitación pública, pero correlativamente crea excepciones. Para esta causal de selección abreviada en particular, por virtud de la Ley se establecieron tres procedimientos diferentes, a. la subasta inversa, b. los acuerdos marco de precios, y c. la bolsa de productos. Hasta el momento, se ha desarrollado el procedimiento de subasta inversa y su reglamentación ha estado consagrada en cuatro decretos reglamentarios diferentes: a. Decreto 066 de 2008, b. Decreto 2474 de 2008, c. Decreto 734 de 2012 y, d. Decreto 1510 de 2013.

El mayor problema se presentó en los casos en los cuales después de agotada la etapa para presentar propuestas y realizada la evaluación, solamente quedara un oferente habilitado, caso en el cual las disposiciones establecían lo siguiente:

\section{Decretos 066 de 2008 y 2474 de 2008, artículo 22}

Si solo un oferente resultare habilitado para participar en la subasta, la entidad ampliará el plazo para la presentación de los documentos habilitantes y la oferta inicial de precio, por el término indicado en los pliegos de condiciones, el cual en ningún caso podrá ser mayor de la mitad del inicialmente previsto. (...)

Parágrafo. Durante la prórroga a que hace referencia el inciso 3 del presente artículo, cualquier interesado podrá presentar oferta, incluyendo a aquellos proponentes que fueron considerados no hábiles para participar en la subasta ${ }^{71}$.

Claramente estas disposiciones están en línea opuesta a la transparencia, a la igualdad, a la eficiencia, a la economía, en fin, al debido proceso administrativo, puesto que no permiten la adjudicación de un proceso a un oferente que puede cumplir todos los presupuestos establecidos por las autoridades competentes pero que por el hecho de ser el único oferente habilitado, debe esperar unos nuevos plazos para competir con participantes que incluso nunca pudieron haber presentado su propuesta. No obstante, mediante

71 Colombia, Decreto 2474 de 2008, por el cual se reglamentan parcialmente la Ley 80 de 1993 y la Ley 1150 de 2007 sobre las modalidades de selección, publicidad, selección objetiva, y se dictan otras disposiciones, 47043 Diario Oficial, 7 de julio de 2008. Disponible en: http:// www.alcaldiabogota.gov.co/sisjur/normas/Norma1.jsp?i=31185 
sentencia del 14 de abril del año 2010 ${ }^{72}$, el Consejo de Estado declaró ilegal la frase "cualquier interesado" del parágrafo, con lo cual eliminó la posibilidad de participación de personas que no se habían presentado inicialmente en el proceso; pero mantuvo la obligación de ampliar el plazo para quienes inicialmente no cumplieron los requisitos que los habiliten. En otras palabras, el tema se resolvió de forma parcial.

\section{Decreto 734 de 2012, artículo 3.2.1.1.5}

Si solo un oferente resultare habilitado para participar en la subasta, la entidad adjudicará el contrato al proponente habilitado, siempre que su oferta no exceda el presupuesto oficial indicado en el pliego de condiciones y ajuste su oferta a un descuento mínimo.

En la misma situación, manifiestamente contrario a la Constitución y a la Ley, el Decreto 734 de 2012 estableció que las entidades podrían adjudicar el contrato siempre y cuando el único oferente habilitado obligatoriamente realice un descuento a favor del Estado, lo que quebrantaba directamente el debido proceso administrativo que por mandato constitucional se sustenta en la eficiencia, eficacia, economía, celeridad de las actuaciones administrativas. Con esta disposición se afectaba directamente el principio de planeación de la contratación pública, puesto que por esencia las autoridades competentes para adelantar la selección de contratistas, previamente deben contar con los estudios de mercado que permitan identificar los presupuestos necesarios para definir el valor de los bienes o servicios a adquirir y con ello retribuir en justicia a los particulares que cooperan con el Estado. No obstante la disposición bajo estudio dejaba el mensaje de que en todo caso los bienes o servicios a adquirir podían ser conseguidos a un menor precio que el inicialmente previsto por la entidad.

\section{Decreto 1510 de 2013, artículo 41}

5. Si en el proceso de contratación se presenta un único oferente cuyos bienes o servicios cumplen con la ficha técnica y está habilitado, la entidad estatal

72 Consejo de Estado, radicación 36054 B, sentencia de 14 de abril de 2010, consejero ponente Enrique Gil-Botero. Disponible en: http://190.24.134.114:8080/WebRelatoria/ce/index.xhtml 
puede adjudicarle el contrato al único oferente si el valor de la oferta es igual o inferior a la disponibilidad presupuestal para el contrato, caso en el cual no hay lugar a la subasta inversa.

Fue necesario que pasaran más de cinco años para que se aplicara la lógica en estos procesos y en los casos de tener un solo oferente habilitado en el procedimiento de subasta inversa, se permita adjudicar el contrato siempre y cuando se cumplan los parámetros mínimos de selección. 


\section{CONCLUSIONES}

En nuestro Estado de Derecho, el derecho al debido proceso involucra el agotamiento de una actuación administrativa previa a la expedición de un acto jurídico. Este acto jurídico - como ha quedado expuesto - puede ser un acto administrativo o un contrato.

Específicamente, en los contratos estatales, se identifica la presencia de unos intereses muy importantes para cada una de las partes, razón por la cual el Estado - para satisfacer sus necesidadesbusca la cooperación de los particulares que, a su turno, buscan satisfacer sus necesidades propias. Esto hace que la aplicación del debido proceso en la selección de ese particular colaborador del Estado, necesariamente tenga un cuidado muy significativo, puesto que aquí se requerirá un esfuerzo mayor para hacer prevalecer la igualdad, la economía, la eficacia y la celeridad en las actuaciones administrativas que adelanten las autoridades competentes. Estas actuaciones administrativas constituyen el debido proceso previo a la formación del acto jurídico y precisamente en este punto están los grandes problemas en la protección del debido proceso. Uno de los elementos que constituye el debido proceso es el procedimiento o la forma que se adopte para lograr el fin. Esta forma claramente debe tener sustento en una disposición jurídica como la ley o los actos administrativos, pero en el caso particular de nuestro ordenamiento jurídico colombiano se ha tornado muy infortunado, sobre todo en entre los años 2007 y 2015.

En efecto, la inestabilidad y la falta de criterio en la toma de decisiones sobre los procedimientos que orienten la selección de contratistas, generan consecuencias nefastas para la protección de un debido proceso que oriente la adopción de decisiones por parte del Estado. En esa medida, violar la consagración del debido proceso constituye un atentado virulento para la existencia del Estado de Derecho, que tiene como fin la consagración de la justicia, pero esta solamente se alcanza en la medida en que las decisiones a las cuales están sometidos los particulares se orienten por unas formas claras que generen seguridad. Así las cosas, al afectarse la forma por la cual se orienta el debido proceso, implícitamente se afecta uno de los pilares que soporta el Estado de Derecho. Esto es la justicia, la cual desaparece en la medida en que las decisiones adoptadas se 
deriven de actuaciones arbitrarias, clandestinas o confusas. Entonces, cuando las actuaciones administrativas se soportan en hechos y no en actos, correlativamente se afecta el principio de legalidad que orienta el actuar de las autoridades administrativas, lo que genera un Estado basado en la transgresión de sus propias estructuras.

Al Estado Colombiano le corresponde marcar las pautas claras para el cumplimiento del derecho al debido proceso, en particular, al debido proceso administrativo que orienta la formación de los contratos estatales. Así como lo solicita el Consejo de Estado en una de las providencias mencionadas, el gobierno nacional debe abogar por una seguridad jurídica basada en los principios que la Ley 80 de 1993 quiso implementar para la contratación de servicios y bienes necesarios para cumplir los fines constitucionales, fines trazados desde el artículo segundo de nuestra Carta Política, a contrario sensu, los fines estatales no serán satisfechos y correlativamente la legitimidad del Estado quedará sensiblemente afectada. 


\section{BIBLIOGRAFÍA}

\section{Libros}

Bernardis, Luis Marcelo de, La garantía procesal del debido proceso (Cultural Cuzco S.A. Editores, Lima, 1985).

Berrocal-Guerrero, Luis Enrique, Manual del Acto Administrativo: según la ley, la jurisprudencia y la doctrina ( $5^{\text {a }}$ ed., Librería Ediciones del Profesional, Bogotá, 2009).

Brewer-Carías, Allan R., Principios del procedimiento administrativo en América Latina (Universidad del Rosario, Colegio Mayor de Nuestra Señora del Rosario, Editorial Legis, Bogotá, 2003).

Camargo, Pedro Pablo, El debido proceso (2 ${ }^{\mathrm{a}}$ ed., Editorial Leyer, Bogotá, 2002).

Cassagne, Juan Carlos, Derecho administrativo, tomo II (Editorial Abeledo Perrot, Pontificia Universidad Javeriana, Colección Internacional, Bogotá, 2009).

Chávez-Marín, Augusto Ramón, Los convenios de la administración: entre la gestión pública y la actividad contractual (Editorial Universidad del Rosario, Bogotá, 2008).

García de Enterría, Eduardo \& Fernández, Tomas Ramón, Curso de derecho administrativo, tomo I (Editorial Temis, Palestra, Bogotá, Lima, 2008).

García-Oviedo, Carlos \& Martínez-Useros, Enrique, Derecho administrativo, tomo II ( $9^{\text {a }}$ ed., Editorial E.I.S.A., Madrid, 1968).

Garrido-Falla, Fernando, Las transformaciones del régimen administrativo (Instituto de Estudios Políticos, Madrid, 1962).

Gómez-Lee, Iván Darío, El derecho de la contratación pública en Colombia. Análisis y comentarios al Decreto 1510 de 2013 (Editorial Legis, Bogotá, 2013).

GonzÁlez-PÉrez, Jesús, El derecho a la tutela jurisdiccional efectiva (2a ed., Editorial Civitas, Madrid, 1985).

JÈze, Gaston, Principios generales del derecho administrativo: la técnica jurídica del derecho público francés, tomo I (Julio N. San Millán-Almagro, trad., Editorial Depalma, Buenos Aires, 1948).

Marienhoff, Miguel S., Tratado de derecho administrativo, tomo III, Contratos de la administración pública teorías general y de los contratos en particular (Editorial Abeledo-Perrot, Ediciones Glem, Buenos Aires, 1965).

Monroy-Gálvez, Juan, Introducción al proceso civil (Editorial Temis, Bogotá, 1996).

Morello, Augusto Mario, El proceso justo. Del garantismo formal a la tutela efectiva de los derechos (Abeledo-Perrot, Buenos Aires, 1994).

Parada, Ramón, Derecho administrativo, tomo I, Parte general (Marcial Pons, Ediciones Jurídicas y Sociales, Madrid, Barcelona 2000).

Rodríguez de Santiago, José María, La administración del Estado social (Editorial Marcial Pons, Ediciones Jurídicas y Sociales, Madrid, 2007). 
Santamaría-Pastor, Juan Alfonso, Principios de derecho administrativo, volumen II ( $3^{\mathrm{a}}$ ed., Editorial Centro de Estudios Ramón Areces, S.A., Madrid, 2002).

Santofimio-Gamboa, Jaime Orlando, Tratado de derecho administrativo, tomo II, Acto Administrativo, procedimiento, eficacia, validez (Universidad Externado de Colombia, Bogotá, 2003).

\section{Contribuciones en obras colectivas}

Herrera, Benjamín, Régimen de la exorbitancia, en Estudios de profundización en contratación estatal (Pontificia Universidad Javeriana, Cámara de Comercio de Bogotá, Bogotá, 1997).

\section{Revistas}

García de Enterría Martínez-CARAnde, EduARdo, La figura del contrato administrativo, 41 Revista de administración pública, 99-130 (1963). Disponible en: http://dialnet. unirioja.es/descarga/articulo/2113075.pdf

Rojas-Franco, EnriQue, El debido procedimiento administrativo, 67 Derecho PUCP, Revista de la Facultad de Derecho de la Pontificia Universidad Católica del Perú, 177-188 (2011). Disponible en: http://revistas.pucp.edu.pe/index.php/derechopucp/ article/view/3147/3513

\section{Tratados internacionales}

Consejo de Europa, Convenio Europeo para la Protección de los Derechos Humanos y de las Libertades Fundamentales, 4 de noviembre de 1950. Disponible en: http:// www.echr.coe.int/Documents/Convention_SPA.pdf

Organización de Estados Americanos, Convención Americana sobre Derechos Humanos, 22 de noviembre de 1969. Disponible en: http://www.oas.org/dil/esp/ tratados_B-32_Convencion_Americana_sobre_Derechos_Humanos.htm

Organización de Naciones Unidas, Declaración Universal de Derechos Humanos, 1948. Disponible en: http://www.un.org/es/documents/udhr/

Organización de Naciones Unidas, Pacto Internacional de Derechos Civiles y Políticos (PIDCP), 16 de diciembre de 1966. Disponible en: http://www.humanium.org/ es/derechos-civiles-politicos/

Organización de Naciones Unidas, Pacto Internacional de Derechos Económicos, Sociales y Culturales (PIDESC), 16 de diciembre de 1966. Disponible en: http:// www.humanium.org/es/pacto-internacional-de-derechos-economicos-socialesy-culturales/ 


\section{Normatividad colombiana}

Colombia, Constitución de Cundinamarca, suscrita el 30 de marzo de 1811, promulgada el 4 de abril de 1811. Disponible en: http://www.cervantesvirtual. com/obra/constitucion-de-cundinamarca-30-de-marzo-de-1811-y-promulgadael-4-de-abril-de-1811--0/, http://www.cervantesvirtual.com/servlet/ SirveObras/12478304311266051543213/p0000001.htm\#I_0_

Colombia, Constitución política (1886). Disponible en: http://www.alcaldiabogota.gov. co/sisjur/normas/Norma1.jsp?i=7153

Colombia, Constitución política (1991). Disponible en: http://www.alcaldiabogota.gov. $\mathrm{co/sisjur/normas/Norma1.jsp?i=4125}$

Colombia, Decreto 01 de 1984, por el cual se reforma el Código Contencioso Administrativo, 36439 Diario Oficial, 10 de enero de 1984. Disponible en: http:// www.alcaldiabogota.gov.co/sisjur/normas/Norma1.jsp?i=6543

Colombia, Decreto 066 de 2008, por el cual se reglamenta parcialmente la Ley 1150 de 2007 sobre las modalidades de selección, publicidad y selección objetiva, y se dictan otras disposiciones, 46873 Diario Oficial, 16 de enero de 2008. Disponible en: http://www.alcaldiabogota.gov.co/sisjur/normas/Norma1.jsp?i=28244

Colombia, Decreto 2474 de 2008, por el cual se reglamentan parcialmente la Ley 80 de 1993 y la Ley 1150 de 2007 sobre las modalidades de selección, publicidad, selección objetiva, y se dictan otras disposiciones, 47043 Diario Oficial, 7 de julio de 2008. Disponible en: http://www.alcaldiabogota.gov.co/sisjur/normas/ Norma1.jsp?i=31185

Colombia, Decreto 1464 de 2010, por el cual se reglamenta parcialmente la Ley 1150 de 2007 en relación con la verificación de las condiciones de los proponentes y su acreditación para el Registro Único de Proponentes a cargo de las Cámaras de Comercio y se dictan otras disposiciones, 47696 Diario Oficial, 30 de abril de 2010. Disponible en: http://www.alcaldiabogota.gov.co/sisjur/normas/Norma1. jsp?i=39442

Colombia, Decreto 2430 de 2011, por el cual se crea la Comisión de Expertos Redactora del Proyecto de Ley de Estatuto General de Contratación de la Administración Pública, 48123 Diario Oficial, 7 de julio de 2011. Disponible en: http://www. alcaldiabogota.gov.co/sisjur/normas/Norma1.jsp?i=43280

Colombia, Decreto 2516 de 2011, por el cual se reglamenta la selección de mínima cuantía, 48128 Diario Oficial, 12 de julio de 2011. Disponible en: http://www. alcaldiabogota.gov.co/sisjur/normas/Norma1.jsp?i=43309

Colombia, Decreto 4170 de 2011, por el cual se crea la Agencia Nacional de Contratación Pública - Colombia Compra Eficiente-, se determinan sus objetivos y estructura, 48242 Diario Oficial, 3 de noviembre de 2011. Disponible en: http:// www.alcaldiabogota.gov.co/sisjur/normas/Norma1.jsp?i=44643

Colombia, Decreto 734 de 2012, por el cual se reglamenta el Estatuto General de Contratación de la Administración Pública y se dictan otras disposiciones, 48400 Diario Oficial, 13 de abril de 2012. Disponible en: http://www.alcaldiabogota. gov.co/sisjur/normas/Norma1.jsp?i=46940 
Colombia, Decreto 1510 de 2013, por el cual se reglamenta el sistema de compras y contratación pública, 48854 Diario Oficial, 17 de julio de 2013. Disponible en: http://www.alcaldiabogota.gov.co/sisjur/normas/Norma1.jsp?i=53776

Colombia, Ley 80 de 1993, por la cual se expide el Estatuto General de Contratación de la Administración Pública, 41094 Diario Oficial, 28 de octubre de 1993. Disponible en: http://www.alcaldiabogota.gov.co/sisjur/normas/Norma1.jsp?i=304

Colombia, Ley 489 de 1998, por la cual se dictan normas sobre la organización y funcionamiento de las entidades del orden nacional, se expiden las disposiciones, principios y reglas generales para el ejercicio de las atribuciones previstas en los numerales 15 y 16 del artículo 189 de la Constitución Política y se dictan otras disposiciones, 43464 Diario Oficial, 30 de diciembre de 1998. Disponible en: http://www.alcaldiabogota.gov.co/sisjur/normas/Norma1.jsp?i=186

Colombia, Ley 1150 de 2007, por medio de la cual se introducen medidas para la eficiencia y la transparencia en la Ley 80 de 1993 y se dictan otras disposiciones generales sobre la contratación con Recursos Públicos, 46691 Diario Oficial, 16 de julio de 2007. Disponible en: http://www.alcaldiabogota.gov.co/sisjur/normas/ Norma1.jsp?i=25678

Colombia, Ley 1437 de 2011, por la cual se expide el Código de Procedimiento Administrativo y de lo Contencioso Administrativo, 47956 Diario Oficial, 18 de enero de 2011. Disponible en: http://www.alcaldiabogota.gov.co/sisjur/normas/ Norma1.jsp?i=41249, http://www.secretariasenado.gov.co/senado/basedoc/ ley_1437_2011.html

Colombia, Ley 1450 de 2011, por la cual se expide el Plan Nacional de Desarrollo 2010-2014, 48102 Diario Oficial, 16 de junio de 2011. Disponible en: http://www. alcaldiabogota.gov.co/sisjur/normas/Norma1.jsp?i=43101

Colombia, Ley 1474 de 2011, por la cual se dictan normas orientadas a fortalecer los mecanismos de prevención, investigación y sanción de actos de corrupción y la efectividad del control de la gestión pública, 48128 Diario Oficial, 12 de julio de 2011. Disponible en: http://www.alcaldiabogota.gov.co/sisjur/normas/Norma1. jsp?i=43292

\section{Normatividad internacional}

Brasil, Ley 9784, que regula el procedimiento administrativo en la administración pública federal, 29 de enero de 1999. Disponible en: http://www.planalto.gov. br/ccivil_03/leis/L9784.htm

España, Ley 30/1992, Ley de Protección Civil, LPC, de 26 de noviembre, de Régimen Jurídico de las Administraciones Públicas y del Procedimiento Administrativo Común, 40300 Boletín Oficial del Estado, BOE, 27 de noviembre de 1992. Disponible en: http://www.boe.es/boe/dias/1992/11/27/pdfs/A40300-40319.pdf

Estados Unidos de América, Constitución política (1787). Disponible en: http:// www.archives.gov/exhibits/charters/constitution_transcript.html, http://www. archives.gov/espanol/constitucion.html

Estados Unidos de América, Quinta Enmienda de la Constitución, 15 de diciembre de 1971. Disponible en: http://www.gpo.gov/fdsys/pkg/GPO-CONAN-1992/pdf/ GPO-CONAN-1992-7.pdf, http://www.archives.gov/espanol/constitucion.html 
Francia, Declaración de los derechos del hombre y del ciudadano, 26 de agosto de 1789. Disponible en: http://www.legifrance.gouv.fr/Droit-francais/Constitution/ Declaration-des-Droits-de-1-Homme-et-du-Citoyen-de-1789, http://www. fmmeducacion.com.ar/Historia/Documentoshist/1789derechos.htm

Inglaterra, Carta Magna, 15 de junio de 1215. Disponible en: http://www.constitution. org/eng/magnacar.htm, http://jorgemachicado.blogspot.com/2008/11/la-cartamagna-de-juan-sin-tierra.html\#fulltext

Inglaterra, Petición de derechos, 7 de junio de 1628. Disponible en: http://www. constitution.org/eng/petright.htm, http://www.unav.es/constitucional/ Materiales/Petition $\% 20$ of $\% 20$ rights $\% 20(1628)$.pdf

\section{Jurisprudencia colombiana}

Consejo de Estado, Sala de Consulta y Servicio Civil, concepto 1454, 16 de octubre de 2002, consejera ponente Susana Montes de Echeverri. Disponible en: http:// www.alcaldiabogota.gov.co/sisjur/normas/Norma1.jsp?i=38183

Consejo de Estado, Sala de lo Contencioso Administrativo, Sección Tercera, sentencia de 3 de diciembre de 2007, consejera ponente Ruth Stella Correa-Palacio.

Consejo de Estado, Sala de lo Contencioso Administrativo, Sección Tercera, radicación 21324, sentencia de 12 de junio de 2014, consejero ponente Enrique Gil-Botero. Disponible en: http://190.24.134.114:8080/WebRelatoria/ce/index.xhtml

Consejo de Estado, Sección Tercera, expediente 45316, auto del 27 de febrero de 2013, consejero ponente Jaime Orlando Santofimio-Gamboa. Disponible en: https:// www.d1tribunaladministrativodelmagdalena.com/images/Jurisprudencia/ Consejo_de_Estado/Auto-45316.pdf

Consejo de Estado, Sección Tercera, expediente 14275 (05229), sentencia de 27 de abril de 2006, consejero ponente Ramiro Saavedra-Becerra. Disponible en: http:// www.alcaldiabogota.gov.co/sisjur/normas/Norma1.jsp?i=21362

Consejo de Estado, Sección Tercera, expediente 24897, sentencia de 19 de noviembre de 2012, consejero ponente Jaime Orlando Santofimio-Gamboa. Disponible en: https://www.d1tribunaladministrativodelmagdalena.com/images/ Jurisprudencia/Consejo_de_Estado/SENTENCIA_UNIFICACION_C.E._ ACTIO_IN_REM_VERSO.pdf

Consejo de Estado, Sección Tercera, radicación 16367, sentencia de 23 de junio de 2010, consejero ponente Enrique Gil-Botero. Disponible en: http://190.24.134.114:8080/ WebRelatoria/ce/index.xhtml

Consejo de Estado, Sección Tercera, radicación 16432, sentencia de 14 de abril de 2010, consejero ponente Mauricio Fajardo-Gómez. Disponible en: http://190.24.134.114:8080/WebRelatoria/ce/index.xhtml

Consejo de Estado, Sección Tercera, radicación 20279 (6217), sentencia de 25 de julio de 2011, consejera ponente Olga Melida Valle de De la Hoz. Disponible en: http://www.alcaldiabogota.gov.co/sisjur/normas/Norma1.jsp?i=44039, http://190.24.134.114:8080/WebRelatoria/ce/index.xhtml 
Consejo de Estado, radicación 36054 B, sentencia de 14 de abril de 2010, consejero ponente Enrique Gil-Botero. Disponible en: http://190.24.134.114:8080/ WebRelatoria/ce/index.xhtml

Corte Constitucional, sentencia C-640-02, 13 de agosto de 2002, magistrado ponente Marco Gerardo Monroy-Cabra. Disponible en: http://www.corteconstitucional. gov.co/relatoria/2002/C-640-02.htm

Corte Constitucional, sentencia C-641-02, 13 de agosto de 2002, magistrado ponente Rodrigo Escobar-Gil. Disponible en: http://www.corteconstitucional.gov.co/ relatoria/2002/c-641-02.htm

Corte Constitucional, sentencia C-731-05, 12 de julio de 2005, magistrado ponente Humberto Antonio Sierra-Porto. Disponible en: http://www.corteconstitucional. gov.co/relatoria/2005/c-731-05.htm

Corte Constitucional, sentencia C-1189-05, 22 de noviembre de 2005, magistrado ponente Humberto Antonio Sierra-Porto. Disponible en: http://www.corteconstitucional. gov.co/relatoria/2005/c-1189-05.htm

Corte Constitucional, sentencia C-980-10, 1 de diciembre de 2010, magistrado ponente Gabriel Eduardo Mendoza-Martelo. Disponible en: http://www. corteconstitucional.gov.co/relatoria/2010/c-980-10.htm

Corte Constitucional, sentencia C-089-11, 16 de febrero de 2011, magistrado ponente Luis Ernesto Vargas-Silva. Disponible en: http://www.corteconstitucional.gov. co/relatoria/2011/c-089-11.htm

Corte Constitucional, sentencia C-818-11, 1 de noviembre de 2011, magistrado ponente Jorge Ignacio Pretelt-Chaljub. Disponible en: http://www.corteconstitucional. gov.co/RELATORIA/2011/C-818-11.htm

Corte Constitucional, sentencia C-610-12, 1 de agosto de 2012, magistrado ponente Luis Ernesto Vargas-Silva. Disponible en: http://www.corteconstitucional.gov. co/relatoria/2012/c-610-12.htm

Corte Constitucional, sentencia T-460-92, 15 de julio de 1992, magistrado ponente José Gregorio Hernández-Galindo. Disponible en: http://www.corteconstitucional. gov.co/relatoria/1992/t-460-92.htm

Corte Constitucional, sentencia T-1013-99, 10 de noviembre de 1999, magistrado ponente Alfredo Beltrán-Sierra. Disponible en: http://www.corteconstitucional.gov.co/ relatoria/1999/t-1013-99.htm

Corte Constitucional, sentencia T-009-00, 18 de enero de 2000, magistrado ponente Eduardo Cifuentes-Muñoz. Disponible en: http://www.corteconstitucional.gov. co/relatoria/2000/t-009-00.htm

Corte Constitucional, sentencia T-1263-01, 29 de noviembre de 2001, magistrado ponente Jaime Córdoba-Triviño. Disponible en: http://corteconstitucional.gov. co/relatoria/2001/T-1263-01.htm

Corte Constitucional, sentencia T-149-02, 1 de marzo de 2002, magistrado ponente Manuel José Cepeda-Espinosa. Disponible en: http://www.corteconstitucional. gov.co/relatoria/2002/t-149-02.htm 
Corte Constitucional, sentencia T-525-06, 11 de julio de 2006, magistrado ponente Clara Inés Vargas-Hernández. Disponible en: http://www.corteconstitucional.gov.co/ relatoria/2006/t-525-06.htm

Corte Constitucional, sentencia T-796-06, 21 de septiembre de 2006, magistrado ponente Clara Inés Vargas-Hernández. Disponible en: http://www.corteconstitucional. gov.co/relatoria/2006/t-796-06.htm 